\title{
Critical review of standards for indoor thermal environment and air quality
}

Khovalyg, Dolaana; Kazanci, Ongun Berk; Halvorsen, Hanne; Gundlach, Ida; Bahnfleth, William P.; Toftum, Jørn; Olesen, Bjarne W.

\section{Published in:}

Energy and Buildings

Link to article, DOI:

10.1016/j.enbuild.2020.109819

Publication date:

2020

Document Version

Peer reviewed version

Link back to DTU Orbit

Citation (APA):

Khovalyg, D., Kazanci, O. B., Halvorsen, H., Gundlach, I., Bahnfleth, W. P., Toftum, J., \& Olesen, B. W. (2020).

Critical review of standards for indoor thermal environment and air quality. Energy and Buildings, 213, [109819]. https://doi.org/10.1016/j.enbuild.2020.109819

\section{General rights}

Copyright and moral rights for the publications made accessible in the public portal are retained by the authors and/or other copyright owners and it is a condition of accessing publications that users recognise and abide by the legal requirements associated with these rights.

- Users may download and print one copy of any publication from the public portal for the purpose of private study or research.

- You may not further distribute the material or use it for any profit-making activity or commercial gain

- You may freely distribute the URL identifying the publication in the public portal 


\section{Journal Pre-proof}

\section{CRITICAL REVIEW OF STANDARDS FOR INDOOR THERMAL ENVIRONMENT AND AIR QUALITY}

Dolaana Khovalyg, Ongun B. Kazanci, Hanne Halvorsen, Ida Gundlach, William P. Bahnfleth , Jørn Toftum , Bjarne W. Olesen

PII: S0378-7788(19)31471-9

DOI: https://doi.org/10.1016/j.enbuild.2020.109819

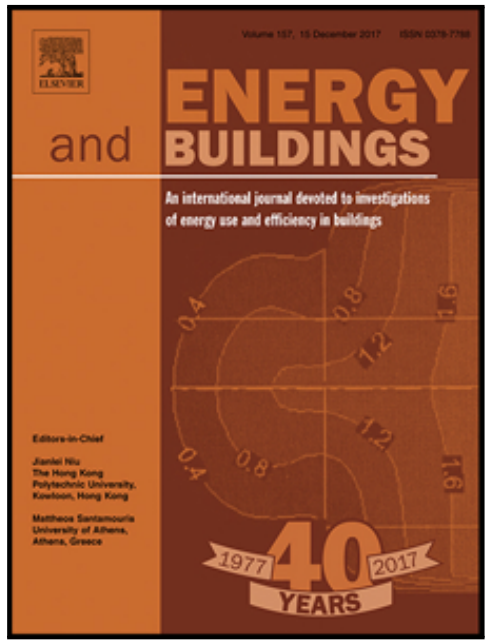

Reference: ENB 109819

To appear in: Energy \& Buildings

Received date: 15 May 2019

Revised date: 23 December 2019

Accepted date: 23 January 2020

Please cite this article as: Dolaana Khovalyg, Ongun B. Kazanci, Hanne Halvorsen , Ida Gundlach, William P. Bahnfleth, Jørn Toftum, Bjarne W. Olesen, CRITICAL REVIEW OF STANDARDS FOR INDOOR THERMAL ENVIRONMENT AND AIR QUALITY, Energy \& Buildings (2020), doi: https://doi.org/10.1016/j.enbuild.2020.109819

This is a PDF file of an article that has undergone enhancements after acceptance, such as the addition of a cover page and metadata, and formatting for readability, but it is not yet the definitive version of record. This version will undergo additional copyediting, typesetting and review before it is published in its final form, but we are providing this version to give early visibility of the article. Please note that, during the production process, errors may be discovered which could affect the content, and all legal disclaimers that apply to the journal pertain.

(C) 2020 Published by Elsevier B.V. 


\section{HIGHLIGHTS}

- A critical comparison of the requirements for indoor thermal environment and ventilation for acceptable air quality across international standards such as ISO, EN, and ASHRAE and national standards of China (GB/T), India (ASHRAE), Singapore (SS), and Australia (AS).

- Standards such as ISO, EN, GB/T, and ISHRAE specify multiple categories for indoor environmental quality parameters, while ASHRAE, SS and AS standards provide only acceptable levels.

- Most of the standards provide recommendations for various categories of IEQ by focusing on the perception of IEQ by occupants rather than productivity and well-being as quantitative criteria.

- IEQ parameters such as thermal comfort and air quality are treated separately and without an integrated assessment of various environmental quality-related dimensions. Therefore, there is a need for a method to combine various indoor environmental factors into a unified indicator.

- Adaptation of occupants to indoor environment is considered to a greater extent in thermal comfort-relates standards rather than in standards for ventilation for adequate air quality.

- Regional differences in climate, building typology, and demographics are not adequately covered in the standards. It would be more appropriate for individual countries to use the concepts provided in standards such as EN and ISO and set "local" limiting values considering particular specifics of the region. 


\title{
CRITICAL REVIEW OF STANDARDS FOR INDOOR THERMAL ENVIRONMENT AND AIR QUALITY
}

\author{
Dolaana Khovalyg ${ }^{1 *}$, Ongun B. Kazanci ${ }^{2}$, Hanne Halvorsen ${ }^{2}$, Ida Gundlach ${ }^{2}$, \\ William P. Bahnfleth ${ }^{3}$, Jørn Toftum², Bjarne W. Olesen ${ }^{2}$ \\ ${ }^{1}$ Thermal Engineering for the Built Environment Laboratory, School of Architecture, Civil and \\ Environmental Engineering (ENAC), École Polytechnique Fédérale de Lausanne (EPFL), \\ Lausanne, Switzerland \\ ${ }^{2}$ International Centre for Indoor Environment and Energy (ICIEE), Department of Civil Engineering, \\ Technical University of Denmark, Kgs. Lyngby, Denmark \\ ${ }^{3}$ Indoor Environment Center, Department of Architectural Engineering, Pennsylvania State \\ University, University Park, USA \\ "Corresponding author. Email: dolaana.khovalyg@epfl.ch \\ Postal address: Passage du Cardinal 13B, Fribourg, 1700, Switzerland
}

Quality of the indoor environment has become an important parameter to account for in new and existing buildings due to the increasing number of people spending most of their time indoors. Generally, the design and evaluation of indoor environments in buildings rely on appropriate guidelines and recommendations. National and international IEQ standards specify indoor environmental conditions considered acceptable to most occupants. This publication reviews and critically compares the requirements for indoor thermal environment and ventilation for acceptable air quality across international standards such as ISO, EN and ASHRAE and national standards of China, India, Singapore, and Australia.

The critical analysis of IEQ standards demonstrates that regional differences and diversity factors due to factors such as climate, building typology, demographics, and culture might not be appropriately addressed both in national and international standards, limiting the feasibility of universal indoor environment criteria. In addition to that, most of the standards provide recommendations for various categories of IEQ by focusing on the perception of IEQ by occupants rather than productivity and wellness as quantitative criteria. The review shows that IEQ parameters are treated separately and without an integrated assessment of various environmental quality-related dimensions. Therefore, there is a need for a method to combine various indoor environmental factors into a combined indicator. 


\section{Nomenclature}

$\begin{array}{ll}\text { A } & \text { Room floor area, } \mathrm{m}^{2} \\ \mathrm{C} & \text { Concentration, } \mu \mathrm{g} / \mathrm{m}^{3} \\ \mathrm{G} & \text { Generation rate, } \mu \mathrm{g} / \mathrm{s} \\ \mathrm{N} & \text { Number of occupants } \\ \mathrm{I} & \text { Insulation } \\ \mathrm{q} & \text { Ventilation rate, } \mathrm{L} / \mathrm{s} \\ \mathrm{Q} & \text { Ventilation rate, } \mathrm{m}^{3} / \mathrm{s} \\ \mathrm{V} & \text { Volume, } \mathrm{m}^{3} \\ \mathrm{U} & \text { Air speed, } \mathrm{m} / \mathrm{s} \\ \mathrm{T}_{\mathrm{u}} & \text { Turbulence intensity, } \% . T u=U_{\text {mean }} / U_{R M S} \\ \mathrm{~T} & \text { Temperature, }{ }^{\circ} \mathrm{C} \\ \alpha & \text { A constant to define } \mathrm{T}_{\mathrm{rm}} \text {, equal to } 0.8 \\ \varepsilon & \text { Effectiveness }\end{array}$

\section{Subscripts}

$\begin{array}{ll}\text { air } & \text { related to air } \\ r m & \text { prevailing mean outdoor } \\ \text { op } & \text { operative } \\ c l & \text { related to clothing } \\ r e f & \text { reference } \\ \text { max } & \text { maximum } \\ \text { mean or } m & \text { mean } \\ \text { tot } & \text { total } \\ B & \text { from the building } \\ p & \text { from person } \\ h & \text { related to a substance } \\ i & \text { guideline value } \\ o & \text { related to the supply air } \\ v & \text { related to ventilation }\end{array}$

\section{Greek symbols}

Difference

\section{Abbreviations}

ASHRAE

DR

HVAC

IAQ

IARC

IEQ

ISHRAE

ISO

PMV

PPD

PD

$\mathrm{RH}$

TVOC
American Society of Heating, Refrigerating and Air-Conditioning Engineers Draught rate Heating, ventilation and air-conditioning Indoor air quality Carcinogenic compounds Indoor environmental quality Indian Society of Heating, Refrigerating and Air Conditioning Engineers International Organization for Standardization

Predicted mean vote

Predicted percentage dissatisfied

Percentage dissatisfied

Relative humidity

Total volatile organic compounds 


\section{Introduction}

Growing world population and the fact that people spend almost $90 \%$ of their time indoors [1], makes indoor environmental quality an important parameter to account for in new and existing buildings. Generally, the design and evaluation of the indoor environment in buildings rely on appropriate national and international standards such as ISO, EN, and ASHRAE that are used to specify indoor environmental conditions that can be considered as acceptable to most of the occupants [2]. Indoor environmental quality (IEQ) is characterized by four environmental categories such as thermal comfort, indoor air quality, lighting, and acoustics. It is very important for designers to consider all IEQ factors; however, requirements for each category are often split up in different standards. For example, ASHRAE standards only include one environmental factor - either thermal comfort or ventilation for acceptable indoor air quality. CEN and ISO have tried to integrate various factors into one standard. While they succeeded in including a complete set of requirements for thermal comfort and indoor air quality, they only partly include requirements for lighting and acoustic which are typically referenced in separate standards. Therefore, this publication concentrates on reviewing requirements for indoor thermal comfort and ventilation for adequate indoor air quality only with focus on offices, classrooms, and residences across international standards such as ISO, EN and ASHRAE and national standards of China, India, Singapore and Australia. Table 1 lists focus areas of considered standards. The scope of standards can be divided into three categories: indoor environment in general (ISO 17772, EN 15251, EN 16798, ISHRAE 10001), thermal environment (ISO EN 7730, ASHRAE 55, GB/T 50785, SS 553), and indoor air quality (ASHRAE 62.1, ASHRAE 62.2, AS 1668-2, SS 554). While full title and publication year information is included in Table 1, abbreviated designations will be used in the manuscript to improve readability.

ISO 17772, presents input parameters for system dimensioning and energy calculations for different indoor environmental quality categories. The standard presents input parameters for the thermal environment, lighting, indoor air quality, acoustics, and humidity. The standard is split into two parts. ISO 17772-1 [3] presents input parameters for the design and assessment of energy performance of buildings, while ISO 17772-2 [4] is a user guide that explains how to use part 1. Additional information on topics such as evaluation of the indoor environmental quality and new possibilities to improve the indoor environmental quality and reduce energy use of new buildings (personalized systems, air cleaning technologies, consideration of adapted persons, etc.) are provided in ISO 17772-2.

EN 15251 [5] presents input parameters for system dimensioning and energy calculations for different indoor environmental quality categories for thermal environment, lighting, indoor air quality, and acoustics. The standard is applicable mainly in non-industrial buildings where the criteria for indoor environment are set by human occupancy and where the manufacturing or technological processes do not have a major impact on indoor environment. EN 16798 is a new standard published in 2019 that supersedes EN 15251. The major change from EN 15251 is that the standard is split into a normative part, EN 16798-1 [6], and a technical report part EN 16798-2 TR [7]. The standard is almost identical to the new international standard ISO 17772.

Standards ASHRAE 55 [8], ISO 7730 [9], and GB/T 50785 [10] present methods for predicting the general thermal sensation and degree of discomfort of people exposed to moderate thermal environments based on indoor thermal environmental factors (i.e. temperature, thermal radiation, humidity, air velocity) and personal factors (clothing level and metabolic rate). While ISO 7730 and GB/T 50785 presents three categories for the thermal environment, ASHRAE 55 does not have indoor environmental categories but defines acceptable thermal environment. GB/T 50785 presents, in addition to recommendations about temperature and other thermal environmental parameters, requirements for measuring the thermal 
environment (instruments, parameters, conditions, time and position). GB/T 50785 is applicable both for residential and public buildings.

Standards SS 553 [11] and SS 554 [12] provide minimum requirements for mechanical ventilation and airconditioning aiming to ensure acceptable indoor thermal environment and indoor air quality in commercial, office and institutional buildings. Standards are applicable for air-conditioned buildings running mechanical systems intermittently or continuously.

ASHRAE 62.1 [13] presents ways of achieving acceptable indoor air quality, defined as safe contaminant concentrations and a high proportion of occupant satisfaction. The scope of the standard does not include residential occupancies, which are covered by the standard ASHRAE 62.2. The standard contains requirements related to certain sources, including outdoor air, construction process, moisture, and biological growth, in addition to ventilation rate. ASHRAE 62.2 [14] presents minimum requirements for mechanical and natural ventilation systems to provide acceptable indoor air quality in low-rise residential buildings, defined similarly to ASHRAE 62.1.

Standard AS $\mathbf{1 6 6 8 . 2}$ [15] presents minimum permissible ventilation rates to provide acceptable indoor air quality. The minimum ventilation rates specified are intended to maintain general contaminants (e.g., body odors, volatile organic compounds and the like) at concentrations below exposures that have the potential to cause adverse health effects to a substantial majority of occupants. The standard includes guidelines on outdoor air intake and sections relating to the ventilation of enclosures for health care functions and for enclosures used by vehicles with combustion engines. The standard does not present indoor environmental categories.

ISHRAE 10001 [16] defines the recommended values and methods of measurement including technical specification of the measuring instruments for indoor air quality, thermal comfort, lighting and acoustics. The standard covers regularly occupied built environments in residential and non-residential buildings with low to moderate levels of activity. Both naturally ventilated, mixed-mode and air-conditioned buildings are covered.

Most of the standards specify multiple categories for indoor environmental quality parameters, as shown in Table 2. However, the number of categories varies and not all standards have multiple categories for all parameters. Furthermore, requirements of similarly named categories vary across standards as well:

- ISO 7730 uses alphabetical categories such as A, B, C, but does not state the expectancy level for each of the category

- Standards ISO 17772, EN 15251, and EN 16798 use numerical categorization of expectancy. Category I is used for spaces for very sensitive and fragile persons, while Category II is the normal level of expectancy.

- ASHRAE standards define a single "acceptable" level (typically, 80\% of acceptability) and set parameter values to reach them

- Standard GB/T 50785 labels indoor environment in buildings as I-III, but does not state the expectancy level for each category

- ISHRAE uses "Classes" instead of "Categories", and provides numerical categorization (I-III) for IEQ parameters and alphabetical (A-C) categorization for buildings.

- $\quad$ SS and AS standards do not categorize IEQ parameters, they provide only acceptable levels.

For the ease of comparing IEQ requirements across standards, all categories/classes of standards in this work are referred to as "Categories" and numerical values from I to IV are given to different levels of requirements. The label "Acceptable" indicates that there is a single category for an IEQ parameter. 
Table 1: Scope of Standards

\begin{tabular}{|c|c|c|c|}
\hline $\begin{array}{c}\text { Standard } \\
\text { (short abbreviation) }\end{array}$ & Full title & $\begin{array}{l}\text { Thermal } \\
\text { environment }\end{array}$ & $\begin{array}{l}\mathrm{IAQ} \text { and } \\
\text { ventilation }\end{array}$ \\
\hline \multicolumn{4}{|c|}{ International Standards } \\
\hline $\begin{array}{l}\text { ISO EN 7730:2005 } \\
\text { (ISO 7730) }\end{array}$ & $\begin{array}{l}\text { Ergonomics of the thermal environment - Analytical } \\
\text { determination and interpretation of thermal comfort } \\
\text { using the calculation of the PMV and PPD indices and } \\
\text { local thermal discomfort criteria }\end{array}$ & $\checkmark$ & $x$ \\
\hline $\begin{array}{l}\text { ISO 17772-1:2017 } \\
\text { (ISO 17772) }\end{array}$ & $\begin{array}{l}\text { Energy performance of buildings - Indoor } \\
\text { environmental Quality - Part 1: Indoor environmental } \\
\text { input parameters for the design and assessment of } \\
\text { energy performance of buildings }\end{array}$ & \multirow[t]{2}{*}{$\checkmark$} & \multirow[t]{2}{*}{$\checkmark$} \\
\hline $\begin{array}{l}\text { ISO 17772-2:2018 } \\
\text { (ISO 17772) }\end{array}$ & $\begin{array}{l}\text { Energy performance of buildings - Overall energy } \\
\text { performance assessment procedures - Part 2: } \\
\text { Guideline for using indoor environmental input } \\
\text { parameters for the design and assessment of energy } \\
\text { performance of buildings }\end{array}$ & & \\
\hline $\begin{array}{l}\text { EN 15251:2007 } \\
\text { (EN 15251) }\end{array}$ & $\begin{array}{l}\text { Indoor environmental input parameters for design and } \\
\text { assessment of energy performance of buildings } \\
\text { addressing indoor air quality, thermal environment, } \\
\text { lighting and acoustics }\end{array}$ & $\checkmark$ & $\checkmark$ \\
\hline $\begin{array}{l}\text { EN 16798-1:2019 } \\
\text { (EN 16798) }\end{array}$ & $\begin{array}{l}\text { Energy performance of buildings - Ventilation for } \\
\text { buildings - Part 1: Indoor environmental input } \\
\text { parameters for design and assessment of energy } \\
\text { performance of buildings addressing indoor air quality, } \\
\text { thermal environment, lighting, and acoustics - Module } \\
\text { M1-6 }\end{array}$ & \multirow[t]{2}{*}{$\checkmark$} & \multirow[t]{2}{*}{$\checkmark$} \\
\hline $\begin{array}{l}\text { CEN/TR 16798- } \\
2: 2019 \\
(\text { EN 16798) }\end{array}$ & $\begin{array}{l}\text { Energy performance of buildings. Ventilation for } \\
\text { buildings. Interpretation of the requirements in EN } \\
16798-1 \text {. Indoor environmental input parameters for } \\
\text { design and assessment of energy performance of } \\
\text { buildings addressing indoor air quality, thermal } \\
\text { environment, lighting and acoustics (Module M1-6) }\end{array}$ & & \\
\hline $\begin{array}{l}\text { ASHRAE 55-2017 } \\
\text { (ASHRAE 55) }\end{array}$ & $\begin{array}{l}\text { Thermal Environmental Conditions for Human } \\
\text { Occupancy }\end{array}$ & $\checkmark$ & $x$ \\
\hline $\begin{array}{l}\text { ASHRAE 62.1-2016 } \\
\text { (ASHRAE 62.1) }\end{array}$ & Ventilation for Acceptable Indoor Air Quality & $x$ & $\checkmark$ \\
\hline $\begin{array}{l}\text { ASHRAE 62.2-2016 } \\
\text { (ASHRAE 62.2) }\end{array}$ & $\begin{array}{l}\text { Ventilation and Acceptable Indoor Air Quality in } \\
\text { Residential buildings }\end{array}$ & $x$ & $\checkmark$ \\
\hline \multicolumn{4}{|c|}{ National Standards } \\
\hline $\begin{array}{l}\text { AS } 1668.2(2012) \\
\text { (AS 1668.2) }\end{array}$ & $\begin{array}{l}\text { The use of ventilation and air conditioning in buildings. } \\
\text { Part 2: Mechanical ventilation in buildings (Australia) }\end{array}$ & $x$ & $\checkmark$ \\
\hline $\begin{array}{l}\text { ISHRAE 10001:2016 } \\
\text { (ISHRAE 10001) }\end{array}$ & Indoor environmental quality standard (India) & $\checkmark$ & $\checkmark$ \\
\hline
\end{tabular}




\begin{tabular}{l|l|c|c}
\hline $\begin{array}{l}\text { GB/T 50785-2010 } \\
\text { (GB/T 50785) }\end{array}$ & $\begin{array}{l}\text { Indoor environmental pollution control of civil building } \\
\text { engineering (China) }\end{array}$ & $\checkmark$ & $\mathbf{x}$ \\
\hline $\begin{array}{l}\text { SS 553:2016 } \\
\text { (SS 553) }\end{array}$ & $\begin{array}{l}\text { Code of practice for air-conditioning and mechanical } \\
\text { ventilation in buildings (Singapore) }\end{array}$ & $\checkmark$ & $\checkmark$ \\
\hline SS 554:2016 & $\begin{array}{l}\text { Code of practice for indoor air quality for air- } \\
\text { (SS 554) }\end{array}$ & $\checkmark$ & $\checkmark$ \\
\hline
\end{tabular}

Table 2: Indoor environmental classes in the reviewed standards

\begin{tabular}{|c|c|c|c|c|}
\hline \multirow{2}{*}{ Standards } & \multicolumn{4}{|c|}{ Categories } \\
\hline & $\mathrm{I}$ & II & III & IV \\
\hline ISO 17772 & $\begin{array}{c}\text { High: } \\
\text { should be selected } \\
\text { for occupants with } \\
\text { special needs } \\
\text { (children, elderly, } \\
\text { handicapped) }\end{array}$ & $\begin{array}{c}\text { Medium: } \\
\text { normal level used } \\
\text { for design and } \\
\text { operation }\end{array}$ & $\begin{array}{c}\text { Moderate: } \\
\text { will still provide an } \\
\text { acceptable environment. } \\
\text { Some risk of reduced } \\
\text { performance of the } \\
\text { occupants }\end{array}$ & $\begin{array}{c}\text { Low: } \\
\text { should only be } \\
\text { used for a short } \\
\text { time of the year } \\
\text { or in spaces with } \\
\text { very short time of } \\
\text { occupancy }\end{array}$ \\
\hline ISO 7730 & $A$ & $B$ & $\mathrm{C}$ & -- \\
\hline $\begin{array}{l}\text { EN 15251, } \\
\text { EN } 16798\end{array}$ & $\begin{array}{c}\text { High level of } \\
\text { expectation (spaces } \\
\text { occupied by very } \\
\text { sensitive and fragile } \\
\text { persons with special } \\
\text { requirements) }\end{array}$ & $\begin{array}{l}\text { Normal level of } \\
\text { expectation and } \\
\text { should be used for } \\
\text { new buildings and } \\
\text { renovations }\end{array}$ & $\begin{array}{l}\text { Moderate level of } \\
\text { expectation and may be } \\
\text { used for existing } \\
\text { buildings }\end{array}$ & $\begin{array}{c}\text { Values outside the } \\
\text { criteria for I-III } \\
\text { categories. This } \\
\text { Category should } \\
\text { only be accepted } \\
\text { for a limited part } \\
\text { of the year }\end{array}$ \\
\hline \multirow{2}{*}{ ISHRAE 10001} & Class I: aspirational & Class II: acceptable & Class II: min. acceptable & -- \\
\hline & Class A: exceptional & Class B: moderate & Class C: acceptable & \\
\hline GB/T 50785 & 1 & II & III & -- \\
\hline
\end{tabular}




\section{Indoor thermal environment}

Criteria for the thermal environment can be expressed as overall thermal comfort index values Predicted Mean Vote (PMV) and Predicted Percent Dissatisfied (PPD) or as minimum and maximum values for the operative temperature. Most standards include both criteria, and a few uses one or the other. Additionally, local discomfort is considered for the complete characterization of the indoor thermal environment.

\subsection{PMV and PPD}

Standards specify particular values for predicted percentage dissatisfied (PPD) and predicted mean vote (PMV). Limits of PMV for different categories across six standards ISO 7730, EN 15251, EN 16798, EN 17772, ASHRAE 55 and GB/T 50785 are shown in Figure 1, and the requirements for PPD are illustrated in Figure 2. ISHRAE 10001 does not specify criteria for the overall thermal comfort index value. To ease the reading of the figures in this review, it is important to note that each subsequent category expands the range of the previous (higher) category.

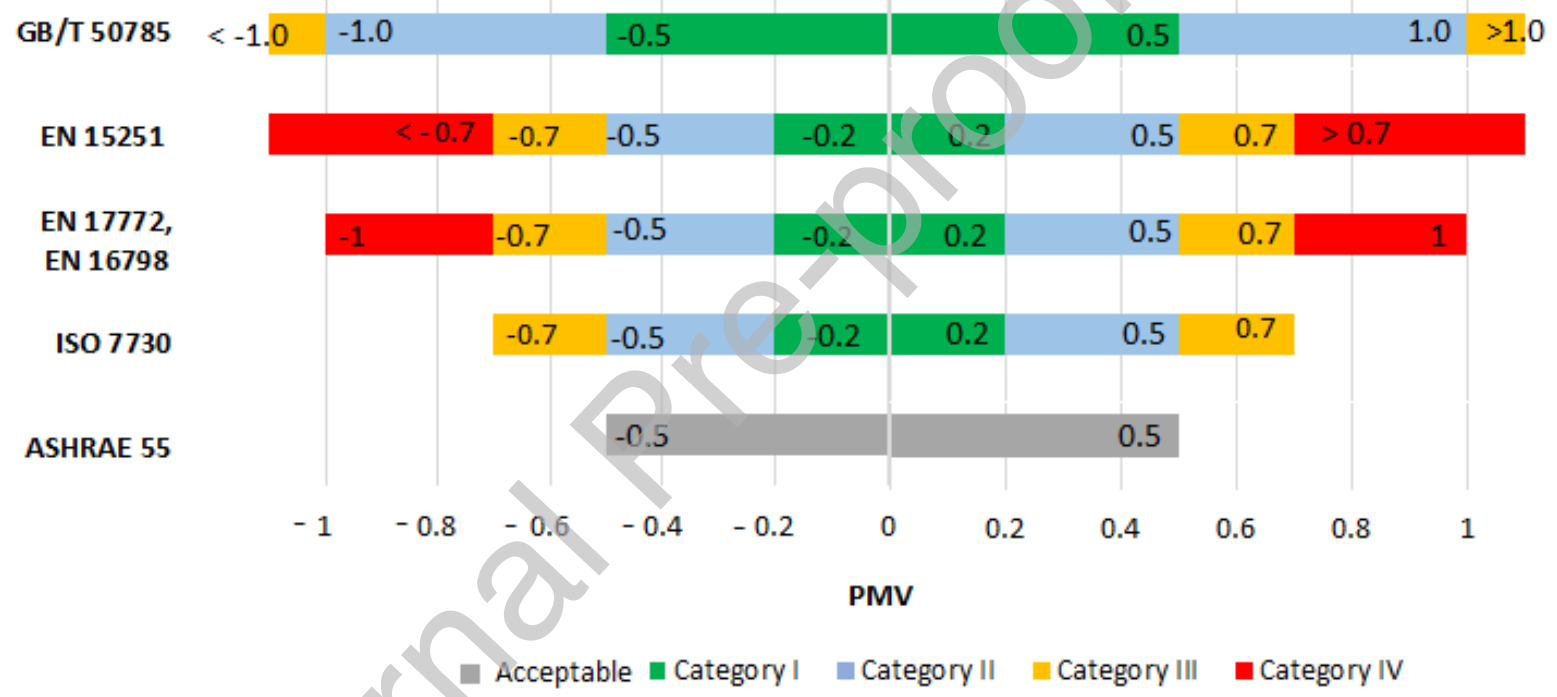

Figure 1: Predicted Mean Vote (PMV) limits

As Figure 2 illustrates, GB/T 50785 aims for a PPD of 10\% for whole-body thermal sensation in their highest indoor environmental class. This is the same level as ASHRAE 55 defines as acceptable and the same as Category II for ISO 7730, ISO 17772, EN 15251 and EN 16798. These standards (ISO 7730, ISO 17772, EN 15251 and EN 16798) make very similar recommendations, with a PPD of $6 \%$ for Category I and PPD of 15 \% for Category III. The Category IV varies slightly for these standards, with the new standards ISO 17772 and EN 16798 agreeing on PPD under $25 \%$. This corresponds to Category II of GB/T 50785. 


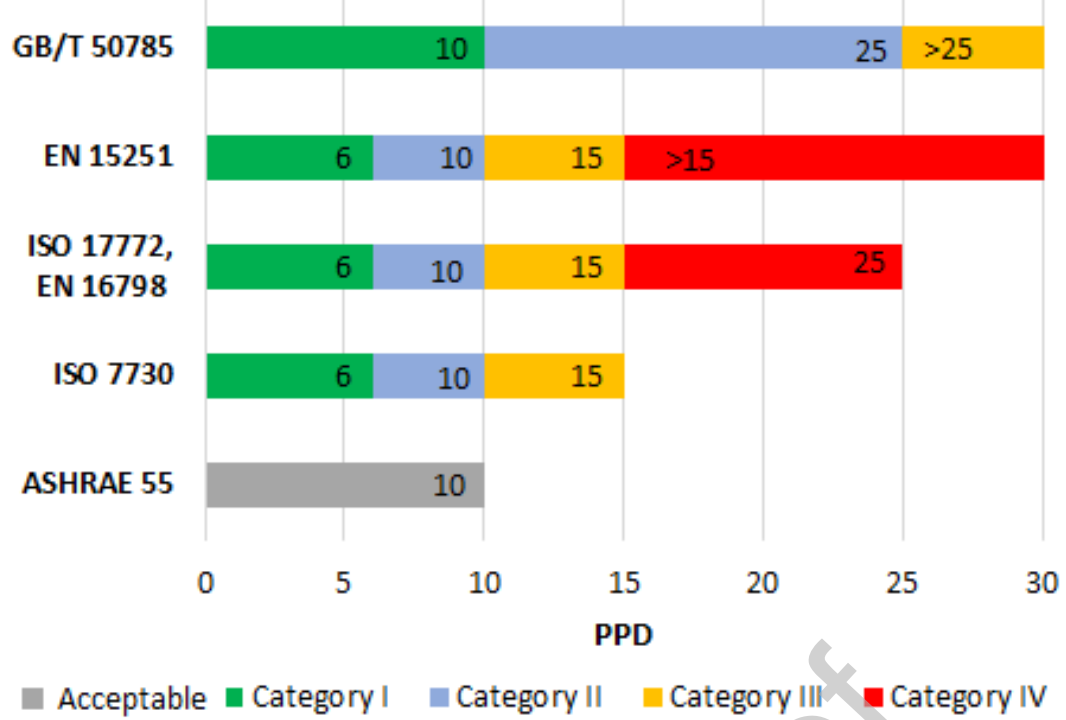

Figure 2: Comparison of Predicted Percentage Dissatisfied (PPD)

It is important to remember that PMV-PPD is not a model trying to predict human responses. It is agreed consensus standardized method to use for evaluation and comparison of thermal environments and to explain the relative importance of the parameters. In real environments, it is very difficult to "measure" PMV-PPD accurately due to the big uncertainty of measuring and predicting clothing level and activity level. Therefore, in real environments, the PMV-PPD categories are used to establish categories for room temperatures (operative temperature) assuming fixed values for activity and clothing.

\subsection{Operative temperature limits}

All standards related to thermal environment recommend indoor temperatures based on standard parameters affecting thermal comfort. For mechanically conditioned buildings thermal comfort depends on the four physical (air temperature, mean radiant temperature, velocity, humidity) and two personal (metabolic rate, clothing insulation) parameters. In case of the absence of mechanical conditioning (e.g. free-running buildings), optimal or neutral operative temperature is a function of the running mean outdoor temperature that considers the weather of preceding days.

\subsubsection{Thermal comfort requirements for mechanically heated and cooled indoor spaces}

\section{Operative temperatures for air speed less than $0.2 \mathrm{~m} / \mathrm{s}$}

Most of the standards, specifically ASHRAE 55, ISO 7730 and GB/T 50785, provide graphical and analytical comfort zone methods to define operative temperature values for a wide range of input parameters such as air speeds and humidity (relative or absolute). To compare operative temperature limits fairly across standards, a reference combination of parameters is listed in Table 3. Acceptable values of environmental (air speed, turbulence intensity, humidity) and personal (clothing insulation) parameters can vary depending on the season and the type of building (residential, non-residential). Therefore, operative temperature limits are provided in Figure 3 both for summer season, when clothing insulation is the lowest, and winter season, when clothing insulation is the highest. EN 15251 uses terms "heating season" and "cooling season" instead of "winter" and "summer", and those terms were kept on Figure 3 as indicated in the original source. Some countries as Singapore will have cooling season (summer) the whole year round. 
Table 3: Reference parameter values for operative temperature comparison (buildings with mechanical cooling and heating)

\begin{tabular}{|c|c|c|c|c|c|c|}
\hline Standard & Categories & $U_{\text {air, } \max }(\mathrm{m} / \mathrm{s})$ & Tu (\%) & $\begin{array}{c}\text { Clothing } \\
\text { insulation (clo) }\end{array}$ & $\begin{array}{l}\text { Metabolic } \\
\text { rate (met) }\end{array}$ & Humidity \\
\hline EN 15251 & all & 0.2 & -- & $0.5^{\mathrm{a}} / 1.0^{\mathrm{b}}$ & 1.2 & $50 \% \mathrm{RH}$ \\
\hline ISO 17772 & all & 0.2 & -- & $0.6^{a} / 1.0^{b}$ & 1.2 & $50 \% \mathrm{RH}$ \\
\hline EN 16798 & all & 0.1 & $30-60$ & $0.5^{\mathrm{a}} / 1.0^{\mathrm{b}}$ & 1.2 & $50 \% \mathrm{RH}$ \\
\hline \multirow{3}{*}{ ISO 7730} & $A$ & $0.12^{\mathrm{a}} / 0.10^{\mathrm{b}}$ & \multirow{3}{*}{40} & \multirow{3}{*}{$0.5^{a} / 1.0^{b}$} & \multirow{3}{*}{1.2} & \\
\hline & B & $0.19^{\mathrm{a}} / 0.16^{\mathrm{b}}$ & & & & $60 \%^{\mathrm{a}} / 40 \%^{\mathrm{b}}$ \\
\hline & C & $0.24^{a} / 0.21^{b}$ & & & & $\mathrm{RH}$ \\
\hline ASHRAE $55^{\mathrm{C}}$ & acceptable & 0.1 & -- & $0.5^{a} / 1.0^{b}$ & $1-1.3$ & $50 \% \mathrm{RH}$ \\
\hline \multirow[t]{2}{*}{ GB/T 50785} & 1 & 0.15 & \multirow{2}{*}{$40^{\mathrm{a}} / 20^{\mathrm{b}}$} & \multirow{2}{*}{$0.5^{\mathrm{a}} / 1.0^{\mathrm{b}}$} & \multirow{2}{*}{$1-1.3$} & $<12 \mathrm{~g} / \mathrm{kg}$ \\
\hline & II & $0.25^{\mathrm{a}} / 0.20^{\mathrm{b}}$ & & & & dry air \\
\hline ISHRAE 10001 & all & 0.2 & -- & $0.5^{a} / 1.0^{b}$ & Low & $20-70 \% \mathrm{RH}$ \\
\hline SS 553, SS 554 & acceptable & 0.3 & -- & & - & $\begin{aligned} & <65 \%{ }^{\mathrm{d}} \\
<70 \% & \\
< & \mathrm{RH}\end{aligned}$ \\
\hline
\end{tabular}

a - summer (cooling season), ${ }^{b}$ - winter (heating season), ${ }^{c}$ - provides comfort zone for elevated air speed (a velocity of $0.1 \mathrm{~m} / \mathrm{s}$ and air humidity of $50 \% \mathrm{RH}$ is chosen here to fairly compare operative temperatures across standards),

${ }^{d}$ - new buildings, ${ }^{e}$ - existing buildings.

ISO 17772 and EN 16798 give different values of operative temperature depending on whether the values are design values or temperature ranges for hourly calculation of cooling and heating energy. The only difference between the two temperatures is that the minimum temperature for heating design or energy calculations is $18{ }^{\circ} \mathrm{C}$ and not $17^{\circ} \mathrm{C}$ for Category IV for non-residential buildings and $16^{\circ} \mathrm{C}$ instead of $17^{\circ} \mathrm{C}$ in residential buildings. It is worth noting that ISO 17772, EN 16798 and EN 15251 allow for a maximum temperature of $25^{\circ} \mathrm{C}$ for all categories under winter conditions both in residential and office buildings. The minimum temperature during winter in Category IV is $1^{\circ} \mathrm{C}$ lower for residential buildings compared to nonresidential buildings. The main difference between EN 15251 and the proposed EN 16798 is that a new Category IV has been added.

ISHRAE 10001 requires temperatures corresponding to Category III of standards ISO 7730 and EN 15251 for all indoor environmental classes. Singaporean standards SS 553 and SS 554 require an acceptable indoor dry-bulb temperature to be in the range between $23^{\circ} \mathrm{C}$ and $25^{\circ} \mathrm{C}$ at air speeds no more than $0.3 \mathrm{~m} / \mathrm{s}$ at 1.5 $\mathrm{m}$ height from the floor level. The lower temperature is applicable to zones with solar loads to compensate for the effect of radiation on comfort, and the rest of the zones can be at a higher temperature. 


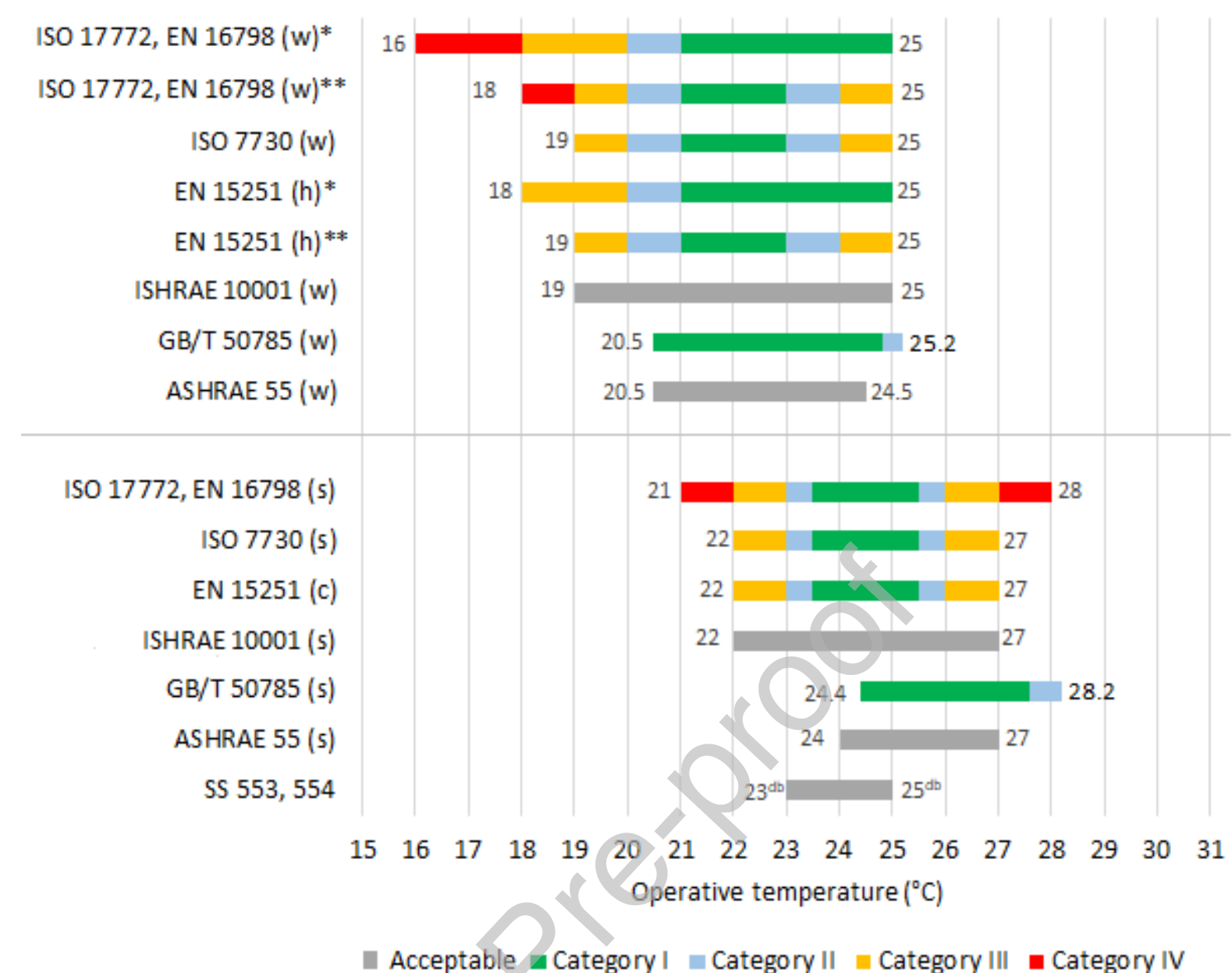

* - residential buildings, living spaces, ** - non-residential spaces (single and landscape offices, conference rooms, auditorium, classrooms, cafeteria and restaurants), ${ }^{\mathrm{db}}$ - dry-bulb temperature

Figure 3: Operative temperature limits for mechanically conditioned indoor space, where (h) - heating season, (c) - cooling season, $(w)$ - winter, $(s)$-summer

\section{Increase of operative temperatures with elevated air speed}

Generally, air speed affects the convective heat loss and the thermal sensation of occupants, therefore, the standards limit acceptable air speed at specified operative temperature ranges for each category. Recommended comfortable air speed is generally below $0.2 \mathrm{~m} / \mathrm{s}$ as indicated in Table 3 for the ranges of operative temperature illustrated in Figure 3. Nevertheless, standards allow elevated air speed created by special equipment (table fans, ceiling fans, personalized ventilation, etc.) in the occupied zone to compensate for higher operative temperature. The possible increase in reference operative temperature due to elevated air speed is shown in Table 4 at different mean air speed values. 
Table 4: Acceptable operative temperatures at elevated air speed

\begin{tabular}{|c|c|c|c|c|}
\hline \multirow{2}{*}{ Standard } & \multirow{2}{*}{$\mathrm{T}_{\text {ref }}\left({ }^{\circ} \mathrm{C}\right)$} & \multicolumn{3}{|c|}{ Acceptable increase in $\mathrm{T}_{\text {op }}(\mathrm{K})$} \\
\hline & & $U_{m, \text { air }}=0.6 \mathrm{~m} / \mathrm{s}$ & $U_{\mathrm{m}, \text { air }}=0.9 \mathrm{~m} / \mathrm{s}$ & $U_{\mathrm{m}, \text { air }}=1.2 \mathrm{~m} / \mathrm{s}$ \\
\hline ISO $7730^{\mathrm{a}}$ & 26 & 2 & 2.7 & 3.3 \\
\hline ISO 17772, EN 16798 & $>25$ & 1.2 & 1.8 & 2.2 \\
\hline EN 15251 & 26 & 2.1 & 2.8 & 3.3 \\
\hline $\begin{array}{l}\text { ASHRAE } \\
55\end{array}$ & $\begin{array}{c}>25 \\
\text { (adaptive T range) }\end{array}$ & 1.2 & 1.8 & 2.2 \\
\hline ISHRAE 10001 & 26 & 2 & 2.7 & 3.3 \\
\hline GB/T 50785 & 27.5 & 2.2 & 3.1 & 3.5 \\
\hline
\end{tabular}

a - ISO 7730 for light sedentary activity does not recommend exceeding air speed of $0.82 \mathrm{~m} / \mathrm{s},{ }^{b}$ - under summer comfort conditions ( $1.2 \mathrm{met}, 0.5 \mathrm{clo}$ ).

Acceptable increase of air speed and temperature from ISO 17772, EN 16798, ISHRAE 10001 is provided in an informative chart shown in Figure 4; however, the mean radiant temperature should be known in order to use the chart. Combinations of air speed and temperature should maintain the same total heat transfer from the skin as a reference point of $26^{\circ} \mathrm{C}$ and $0.2 \mathrm{~m} / \mathrm{s}$. The chart is valid for sedentary activities (1.2 met) and for summer conditions with typical clothing insulation of $0.5 \mathrm{clo}$. Although ISO 7730 for light sedentary activity does not recommend exceeding air speed of $0.82 \mathrm{~m} / \mathrm{s}$, the standard allows elevated air speed if it is under the direct control of occupants and adjustable in steps no greater than $0.15 \mathrm{~m} / \mathrm{s}$. Recommendations of ISO 7730 are used in ISHRAE 1001 as well. ISO 17772 and EN 16798, similarly to ISO 7730, also warn that air speed over $0.8 \mathrm{~m} / \mathrm{s}$ should be avoided, otherwise normal office paper starts blowing from the desk. In addition to that, ISO 17772 and EN 16798 requires the increased air speed to be under personal control.

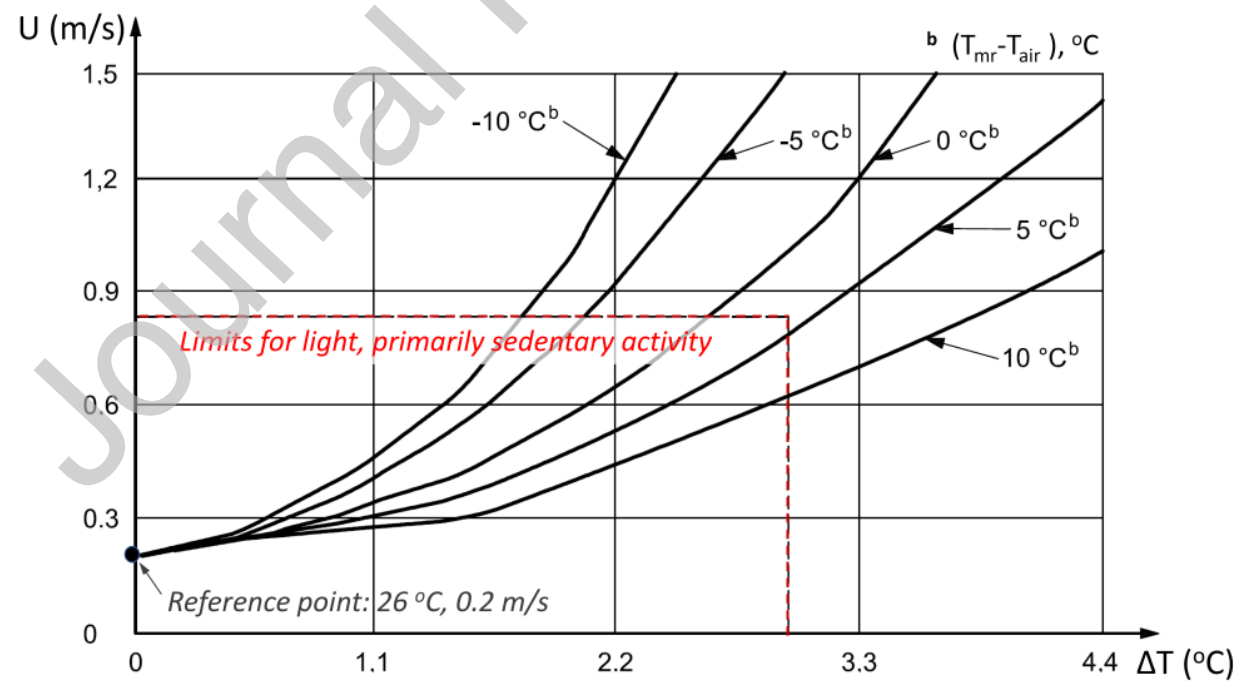

Figure 4: Air speed required to offset increased temperature (0.5 clo, 1.2 met) [9], [16]

ASHRAE 55 splits the acceptable operative temperature range in all spaces within the scope of the standard into air speed regions with required and not required local control of air speed, the flowchart for determining limits is illustrated in Figure 5. When occupants have control, the air speed should be adjustable continuously or in maximum steps of $0.25 \mathrm{~m} / \mathrm{s}$ measured in the occupied zone. There is no air speed limit if the activity level of the occupants can exceed 1.3 met. ASHRAE 55 also provides some guidance on the acceptable increase of operative temperature limits as the result of increased air speed in 
occupant-controlled naturally conditioned spaces. For instance, if the average air speed is $1.2 \mathrm{~m} / \mathrm{s}$ then the upper limit of the operative temperature can be increased by up to $2.2^{\circ} \mathrm{C}$ as listed in Table 4 . The same guidance values are provided in EN 17772 if occupants use table fans, ceiling fans or personal ventilation systems with a boost function.

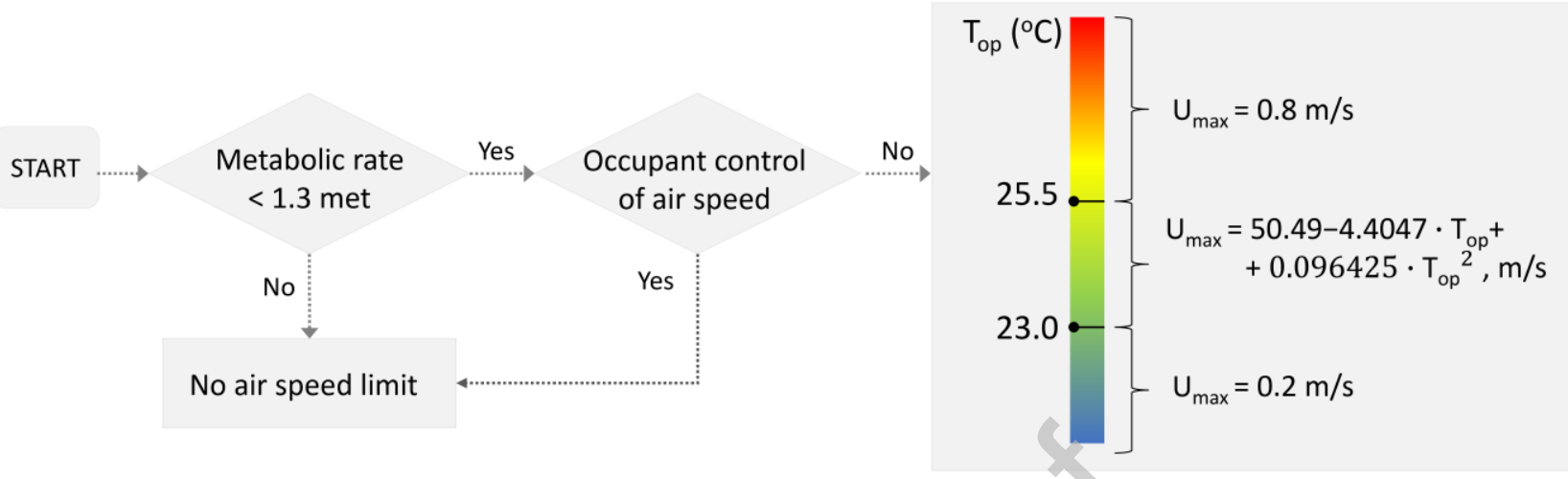

Figure 5: Flowchart for determining limits to air speed accounting for a representative occupant with $I_{c l}<0.7$ clo [8]

The standard GB/T 50785 uses a graphical method similar to the one used in the version of ASHRAE 552013 (Fig. 5.3.3A in [17]). The comfort zone is divided into three different categories: (1) still air ( $<0.15$ $\mathrm{m} / \mathrm{s}),(2)$ increased air speed where control of occupants is not required, and (3) area of increased air speed with required control of occupants. The upper air speed for occupants without control is $0.15 \mathrm{~m} / \mathrm{s}$ for temperatures below $22.5^{\circ} \mathrm{C}$ and $0.8 \mathrm{~m} / \mathrm{s}$ for temperatures over $25.5^{\circ} \mathrm{C}$. The upper limit is $1.2 \mathrm{~m} / \mathrm{s}$ for occupant with control if the metabolic rate is below 1.3 met. GB/T 50785 divides an acceptable range of operative temperatures marked in ASHRAE 55-2013 into two categories: a still air comfort zone $(<0.15$ $\mathrm{m} / \mathrm{s}$ ) is defined as Category I, and the rest of the acceptable area as Category II, unacceptable temperatures are considered as Category III. The update of air speed limits in GB/T 50785 is delayed compared to ASHRAE 55 standard.

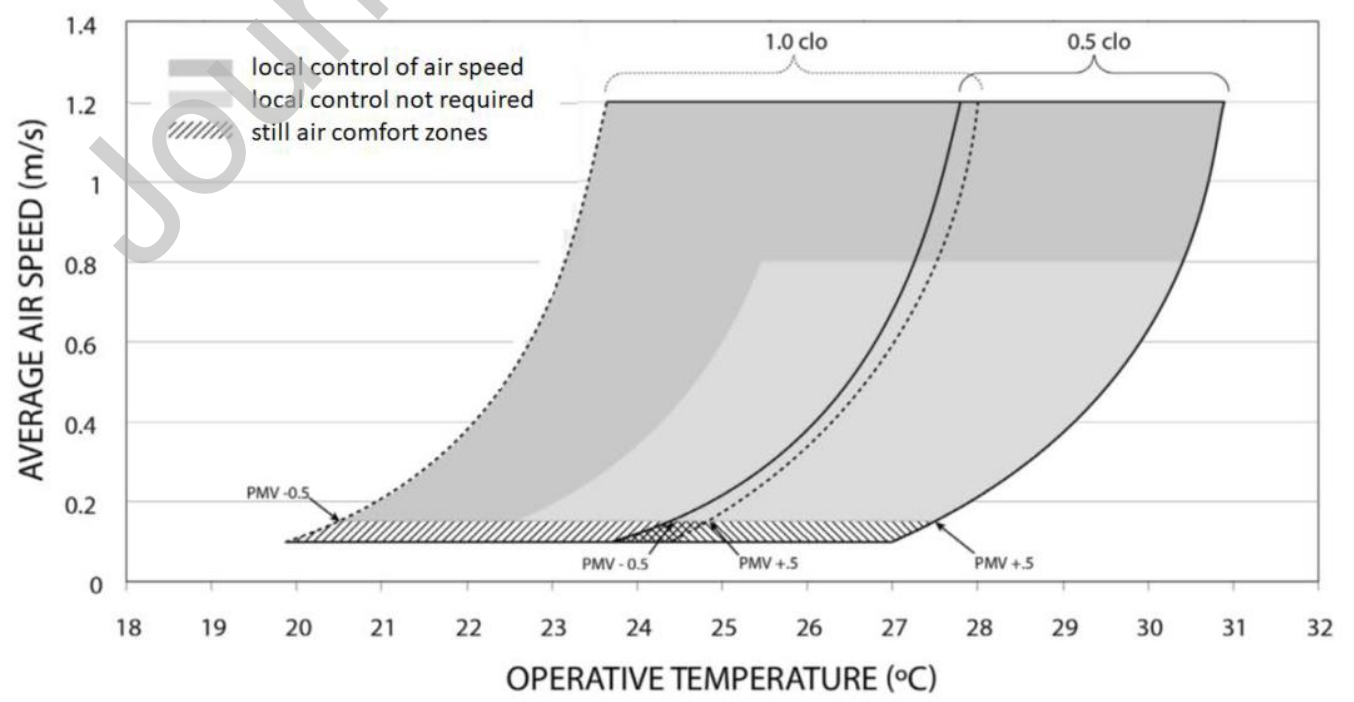

Figure 6: Air velocity required to offset increased air (applicable for sitting position and about 1.1 met) [10] 


\subsubsection{Thermal comfort requirements when no mechanical cooling is used}

Generally, thermal conditioning of buildings can span from entirely mechanically conditioned, when mechanical systems run continuously, to no cooling or heating, when mechanical systems are never used. In-between, a large subset of mixed-mode buildings may have natural ventilation some of the time and mechanical conditioning at others.

Recommended ranges of indoor operative temperatures $\left(T_{o p}\right)$ for naturally conditioned buildings are based on an adaptive comfort model that specifies $T_{\text {op }}$ as a function of prevailing mean outdoor air temperature $T_{r m}$ as listed in Table 5 and Figure 7. Per ASHRAE 55, the prevailing outdoor temperature $T_{r m}$ can be either a simple mean (preferred method) or an exponentially weighted running mean temperature for the day of interest and at least 6 previous days as defined by Eqn. 1. The recommended value of the constant $\alpha$ ranges between 0.6 (slow responding running mean) and 0.9 (fast responding running mean). ISO and EN standards specify daily running mean outdoor temperature as indicated in Eqn. 1.

$$
\begin{aligned}
& T_{r m}=(1-\alpha)\left(T_{o d-1}+\alpha T_{o d-2}+\alpha^{2} T_{o d-3}+\alpha^{3} T_{o d-4}+\alpha^{4} T_{o d-5}+\alpha^{5} T_{o d-6}+\alpha^{6} T_{o d-7}\right) \\
& T_{r m}=\frac{1}{3.8}\left(T_{o d-1}+0.8 T_{o d-2}+0.6 T_{o d-3}+0.5 T_{o d-4}+0.4 T_{o d-5}+0.3 T_{o d-6}+0.2 T_{o d-7}\right)
\end{aligned}
$$

For the adaptive approach to be applicable, ISO 17772, EN 16798 and ASHRAE 55 require that the building does not have mechanical cooling systems installed. A mechanical ventilation system can be running, but air should not be conditioned. ASHRAE 55 also requires that there is no heating system in operation during the period when the adaptive model is used. ISO 17772 and EN 15251 requires that no mechanical cooling is in operation, and the adaptive method only applies outside the heating season. GB/T 50785 specifies no use of "artificial" heating and air conditioning if the building is free-running, only mechanical ventilation without thermal conditioning of the supply air can be used.

ISO 17772 and EN 16798 state that the adaptive method only applies to occupants with sedentary activities (1.0 to 1.3 met) without strict clothing policies providing possibilities to adapt their clothing within a range of at least 0.4 to 1.0 clo. Thermal conditions should be regulated primarily by the occupants through the opening and closing of windows. EN 15251 states the same, without giving numeric ranges for clothing and activity level. ASHRAE 55 requires that the occupants are free to adapt their clothing to the indoor and/or outdoor thermal conditions within a range of at least 0.5 to $1 \mathrm{clo}$, and that the occupants have metabolic rates ranging from 1.0 to 1.3 met.

\begin{tabular}{|c|c|c|c|c|}
\hline Standard & Categories & $\begin{array}{l}\mathrm{T}_{\text {op }}\left({ }^{\circ} \mathrm{C}\right) \text {, } \\
\text { upper limit }\end{array}$ & $\begin{array}{c}\mathrm{T}_{\mathrm{op}}\left({ }^{\circ} \mathrm{C}\right) \\
\text { lower limit }\end{array}$ & $\begin{array}{c}\mathrm{T}_{\mathrm{op}}\left({ }^{\circ} \mathrm{C}\right), \\
\text { applicability range }\end{array}$ \\
\hline \multirow{3}{*}{$\begin{array}{l}\text { ISO 17772, } \\
\text { EN } 16798^{\mathrm{a}}\end{array}$} & 1 & $0.33 * T_{r m}+20.8$ & $0.33 * T_{r m}+15.8$ & $10-30$ \\
\hline & II & $0.33 * \mathrm{~T}_{\mathrm{rm}}+21.8$ & $0.33 * \mathrm{~T}_{\mathrm{rm}}+14.8$ & $10-30$ \\
\hline & III & $0.33 * T_{r m}+22.8$ & $0.33 * \mathrm{~T}_{\mathrm{rm}}+13.8$ & $10-30$ \\
\hline \multirow{3}{*}{ EN $15251^{b}$} & 1 & $0.33 * \mathrm{~T}_{\mathrm{rm}}+20.8$ & $0.33 * \mathrm{~T}_{\mathrm{rm}}+16.8$ & 10-30 (upper limit) \\
\hline & II & $0.33 * T_{r m}+21.8$ & $0.33 * \mathrm{~T}_{\mathrm{rm}}+15.8$ & \multirow{2}{*}{$15-30$ (lower limit) } \\
\hline & III & $0.33 * T_{r m}+22.8$ & $0.33 * \mathrm{~T}_{\mathrm{rm}}+14.8$ & \\
\hline \multirow{3}{*}{ ASHRAE 55} & acceptable (80\%) & $0.31 * \mathrm{~T}_{\mathrm{rm}}+21.3$ & $0.31 * \mathrm{~T}_{\mathrm{rm}}+14.3$ & \multirow{2}{*}{$10-33.5$} \\
\hline & acceptable (90\%) & $0.31 * \mathrm{~T}_{\mathrm{rm}}+21.3$ & $0.31 * \mathrm{~T}_{\mathrm{rm}}+15.3$ & \\
\hline & $I^{d}$ & $0.77 * \mathrm{~T}_{\mathrm{rm}}+12.04$ & $0.87 * T_{r m}+2.76$ & $18-28$ \\
\hline
\end{tabular}

Table 5: Conditions for the adaptive comfort zone applicability (naturally ventilated buildings) 


\begin{tabular}{ccccc}
$\mathrm{GB} / \mathrm{T} 50785^{\mathrm{c}}$ & $\mathrm{II}^{\mathrm{d}}$ & $0.73 * \mathrm{~T}_{\mathrm{rm}}+15.28$ & $0.91^{*} \mathrm{~T}_{\mathrm{rm}}-0.48$ & $16-28\left(30^{\mathrm{f}}\right)$ \\
\cline { 2 - 5 } & $\mathrm{I}^{\mathrm{e}}$ & $0.77 * \mathrm{~T}_{\mathrm{rm}}+9.33$ & $0.87 * \mathrm{~T}_{\mathrm{rm}}-0.31$ & $18-30$ \\
& $\mathrm{II}^{\mathrm{e}}$ & $0.73 * \mathrm{~T}_{\mathrm{rm}}+12.72$ & $0.91 * \mathrm{~T}_{\mathrm{rm}}-3.69$ & $16-28\left(30^{\mathrm{f}}\right)$ \\
\hline
\end{tabular}

a - above a running mean temperature of $25^{\circ} \mathrm{C}$, the limits are based on limited field data, ${ }^{\mathrm{b}}$ - the lower limits are valid between 15 to $30^{\circ} \mathrm{C}^{\circ}{ }^{\mathrm{C}}$ - any operative temperatures beyond the requirements of Categories I and II are considered as Category III, ${ }^{d}$-very cold, cold zone e - hot summer/cold winter, hot summer/warm winter, mild zone, ${ }^{f}$ - maximum temperature of the lower acceptability

40

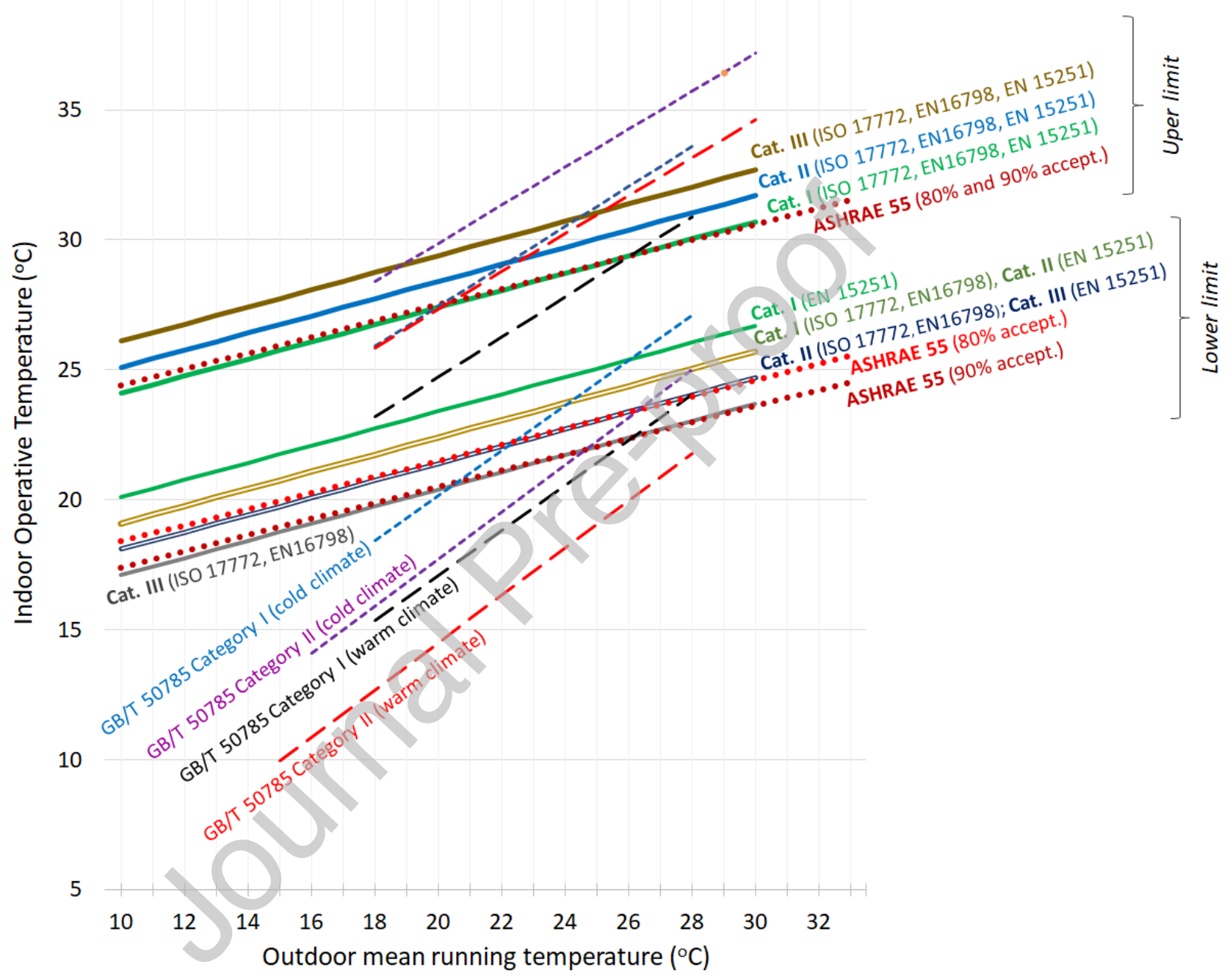

Figure 7: Adaptive thermal comfort zones for naturally conditioned buildings (for EN 15251, the lower limits are valid in the range $15-30^{\circ} \mathrm{C}$ )

Comparison of the lower and upper limits of the adaptive comfort zone listed in Table 5 and shown in Figure 7, reveals the following:

- The standard EN 15251 has the narrowest comfort zone per Category, while ISO 17772 and EN 16798 have the same upper limit but the lower limit is eased by $1 \mathrm{~K}$.

- ASHRAE 55 generally allows for lower temperatures, where the lower limit is practically equal to ISO 17772 and EN 16798 Category III, while the ASHRAE 55 upper temperature limit is practically 
equal to the upper limit of Category I of the standards ISO/EN Category I. Despite the difference in lower limits, the optimal operative temperature indicated in ISO 17772, EN 16798, and EN 15251 is $T_{o p}=0.33 T_{r m}+18.8$. The optimum operative temperature according to ASHRAE 55 is $T_{o p}=$ $0.31 T_{r m}+17.8$, which is closer to the lower limit of the Category I of the standard EN 15251.

- According to GB/T 50785, relations between indoor temperature and outdoor temperature depend on the building and the climate zone. Acceptable operative temperatures in free-running buildings in China have a stronger dependence on the outdoor temperature, i.e., vary over wider ranges, compared to ISO/EN standards and ASHRAE 55, indicating a higher degree of adaptation of people in China.

\subsubsection{Operative temperature limits outside occupied hours}

The values of operative temperature provided in Sections 2.2.1 and 2.2.2 are only enforced during occupied hours. However, EN 16798 states that the operative temperature should be $16-32^{\circ} \mathrm{C}$ all the time, including outside occupied hours.

\subsection{Local thermal discomfort}

Requirements are specified to prevent local thermal discomfort due to draft, vertical air temperature difference between head and ankle, warm or cold floors and radiant temperature asymmetry. All standards covering the topic of thermal comfort (ISO 17772, EN 16798, ASHRAE 55, and GB/T 50785), except ISHRAE 10001, address local discomfort and provide limiting values for the percent dissatisfied (PD) per category of the thermal environment as shown in Figure 8. ISO 7730 clarifies that PD caused by different types of local discomfort or a whole-body discomfort should not be added since often the same persons are sensitive to different types of discomfort. Therefore, such a sensitive person may also easily experience discomfort for the body as a whole.

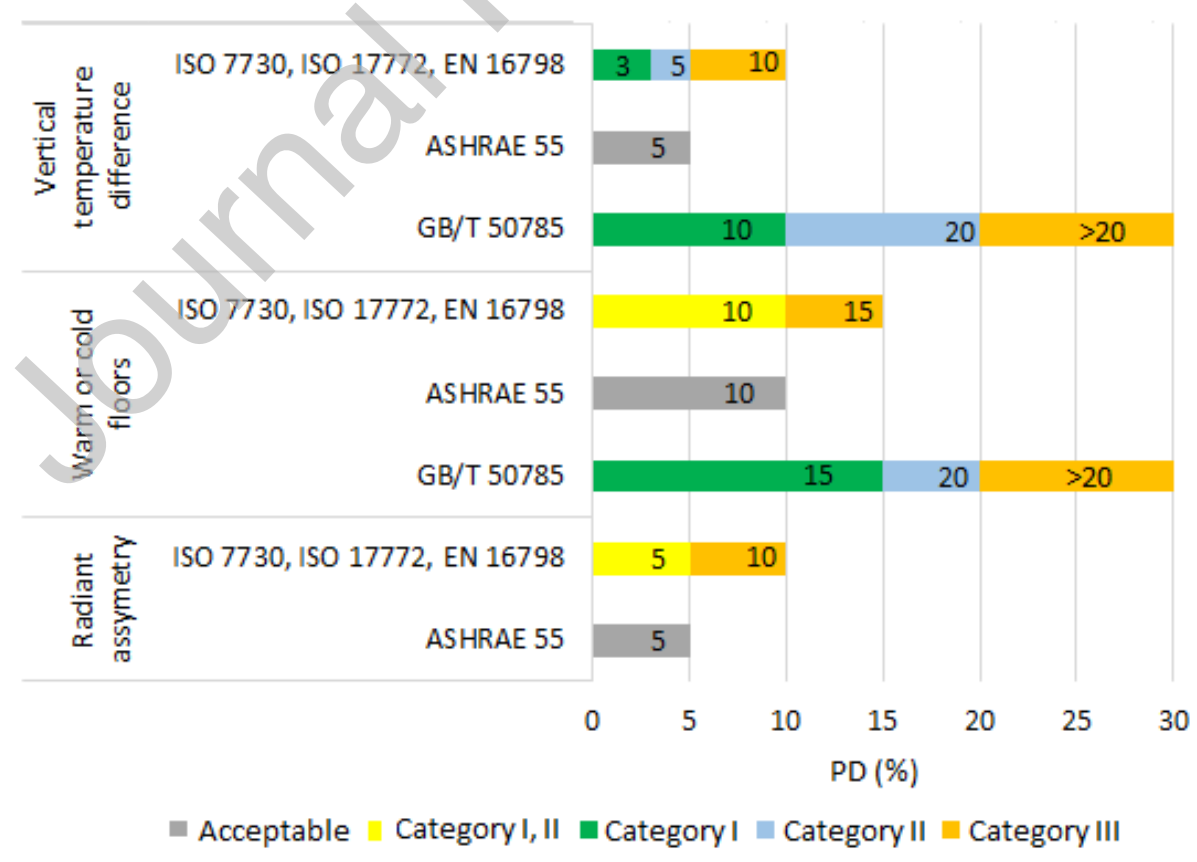

Figure 8: Local discomfort: limits of Percent Dissatisfied (PD) across standards 
In terms of applicability, ISO 7730 states that mainly people performing light sedentary activity are sensitive to local discomfort because the body as a whole is in a neutral thermal state (PMV is close to neutral). At higher activity levels, people are less thermally sensitive and, consequently, the effect of local discomfort could be insignificant. ASHRAE 55 states that requirements for local discomfort are only applicable when representative occupants have a clothing insulation less than 0.7 clo and activity level less than 1.3 met.

\subsubsection{Draft rate}

Draft is an unwanted local cooling of the skin caused by air movement. It is assessed by the draft rating index, DR \%, defined by the Eqn. 3 [18]:

$$
D R=\left(34-T_{o p}\right)\left(U_{m, a i r}-0.05\right)^{0.62}\left(0.37 U_{m, a i r} * T u+3.14\right)
$$

A comparison of the criteria for the acceptable draft rating (DR) is provided in Figure 9. Standards ISO 7730, ISO 17772 and EN 16798 have the same requirements for the draft rating. Draft rating should not exceed 10\% for Category I, 20\% for Category II and 30\% for Category III. ASHRAE 55 gives the same recommendations for maximum draft rating, $\mathrm{DR}=20 \%$, as Category II in the ISO/EN standards. GB/T 50785 keeps Category I at the same level as the ISO/EN standards Category III. ISHRAE 10001 does not provide recommendations to avoid draft.

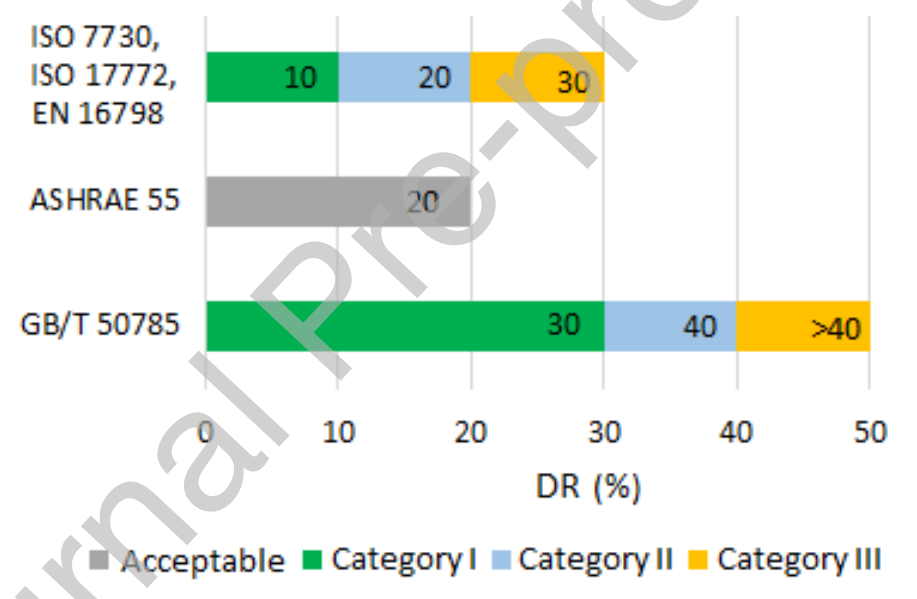

Figure 9: Local discomfort: acceptable draft rating per category

Along with the limiting DR, standards present upper limits for air speed in winter and summer as listed in Table 6. Standards ISO 17772 and EN 16798 give acceptable air speeds for different categories, based on an assumption of an activity level of 1.2 met, turbulence intensity of $40 \%\left(T u=S T D_{v} / U_{\text {mean }}\right)$, and air temperature equal to the operative temperature, set to $20^{\circ} \mathrm{C}$ in winter and $23^{\circ} \mathrm{C}$ in summer. ASHRAE 55 requires average air speed not to exceed $0.15 \mathrm{~m} / \mathrm{s}$ when the operative temperature is below $22.5^{\circ} \mathrm{C}$. Air movement could be caused by down draft from cold surfaces and/or the HVAC systems, but not by office equipment and occupants. Higher air speeds are permitted at higher temperatures, for instance in the summer, either with or without occupancy control. The standard GB/T 50785 refers to ISO 7730 and states that local percentage dissatisfied caused by draught should be less than $20 \%$. The maximum air speed in summer is defined at air temperature of $26{ }^{\circ} \mathrm{C}$ and $\mathrm{T}_{\mathrm{u}}=40 \%$, while winter conditions are $\mathrm{T}_{\text {air }}=18{ }^{\circ} \mathrm{C}$ and $\mathrm{T}_{\mathrm{u}}=20 \%$. ISHRAE 10001 mentions draft as a physical parameter affecting thermal comfort, but a criterion for DR is not given. ISO 7730 provides detailed graphs shown in Figure 10 depicting the dependence of the maximum acceptable mean air speed on local air temperature and turbulence intensity for different DR levels. 
Table 6: Acceptable maximum air speed to avoid draft

\begin{tabular}{cccc}
\hline Standard & Categories & $\begin{array}{c}\mathrm{U}_{\max }(\mathrm{m} / \mathrm{s}), \\
\text { summer }\end{array}$ & $\begin{array}{c}\mathrm{U}_{\max }(\mathrm{m} / \mathrm{s}), \\
\text { winter }\end{array}$ \\
\hline \hline ASHRAE 55 & acceptable & 0.8 & 0.15 \\
\hline GB/T 50785 & all & 0.25 & 0.20 \\
\hline ISO 17772, & I & 0.12 & 0.10 \\
EN 16798 & II & 0.19 & 0.16 \\
& III & 0.24 & 0.21 \\
\hline \hline
\end{tabular}

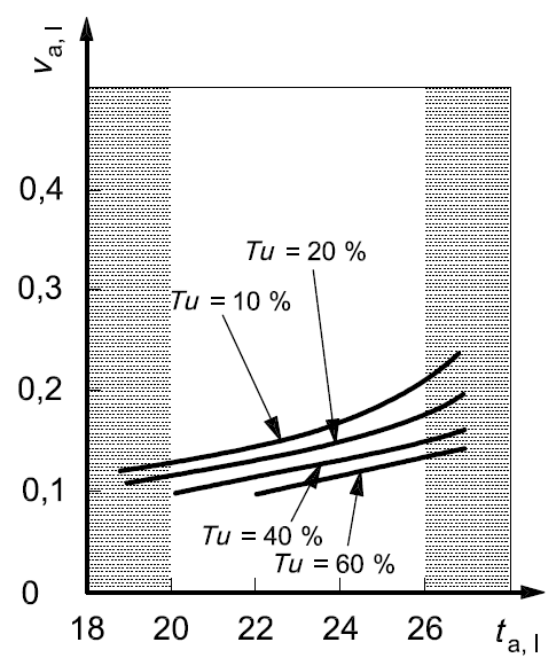

Category A: DR $=10 \%$

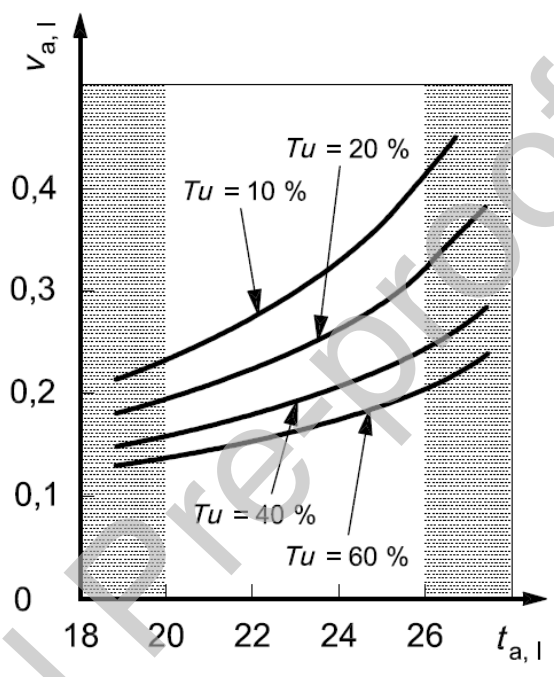

Category B: DR $=20 \%$

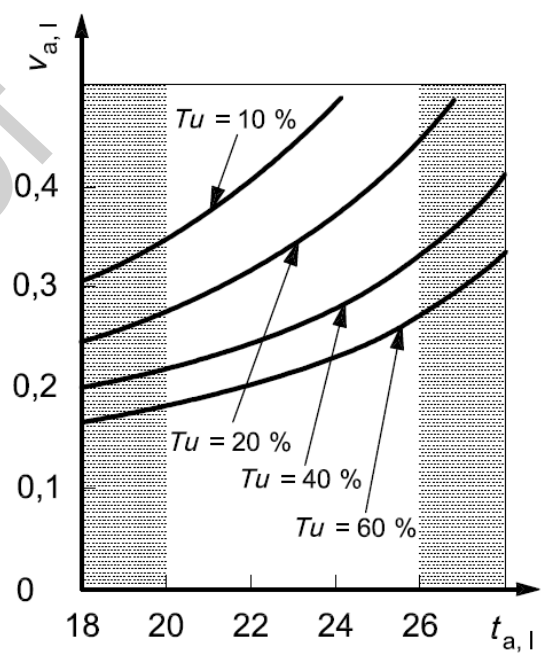

Category C: $\mathrm{DR}=\mathbf{3 0} \%$

Figure 10: Maximum mean air velocity as function of local air temperature and turbulence intensity [9]

\subsubsection{Vertical air temperature difference}

The standards provide recommendations on local discomfort due to vertical temperature differences presented as PD limits or as the maximum allowed temperature difference between head and ankle level (1.1 $\mathrm{m}$ and $0.1 \mathrm{~m}$ above the floor). Recommendations for the maximum temperature difference are shown in Figure 11. A comparison of PPD limits across standards are provided in Figure 8 along with other local discomfort factors for the ease of comparison.

Acceptable vertical temperature difference per ASHRAE 55 is at the same level as ISO/EN Category II, and GB/T 50785 Class I is equal to ISO/EN Category III. In ISHRAE 10001, a requirement for vertical air temperature difference is given only for Category I. The limit of $\Delta T=4 \mathrm{~K}$ for the Category I matches the limit of the GB/T 50785 Category I. No limiting criteria for the percentage dissatisfied due to vertical air temperature difference is provided by ISHRAE 10001. 


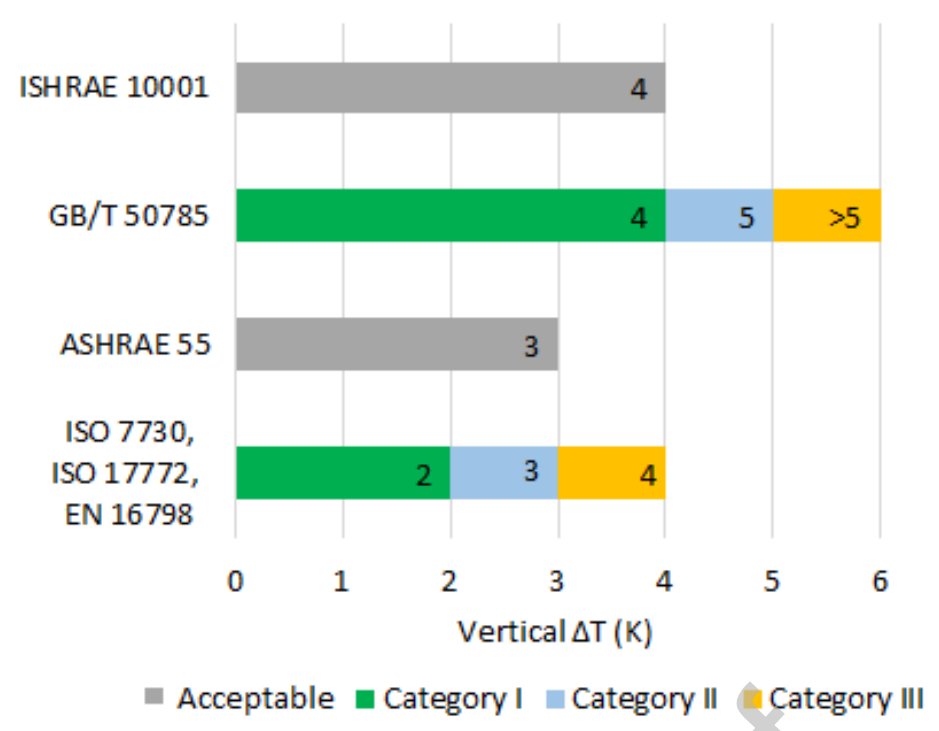

Figure 11: Acceptable vertical temperature difference

\subsubsection{Warm or cool floor}

The criteria for warm or cool floors can be given either as PD limits as illustrated in Figure 8 or as floor surface temperature range as shown in Figure 12.

Acceptable level of floor surface temperature per ASHRAE 55 is at the same level as ISO/EN Category I and II. Limits of the ISHRAE 10001 Category I and GB/T 50785 Category I is at the same level as ISO/EN Category 3. In ISHRAE 10001, a requirement for the warm or cool floor is given only for Category I and no criteria are given for the percentage dissatisfied. In $\mathrm{GB} / \mathrm{T}$ 50785, no value for the floor surface temperature range is given, but the values can be calculated either from a graphical representation of the relationship between the surface temperature of the floor and the percentage dissatisfied or defined from an equation showing the same relationship.

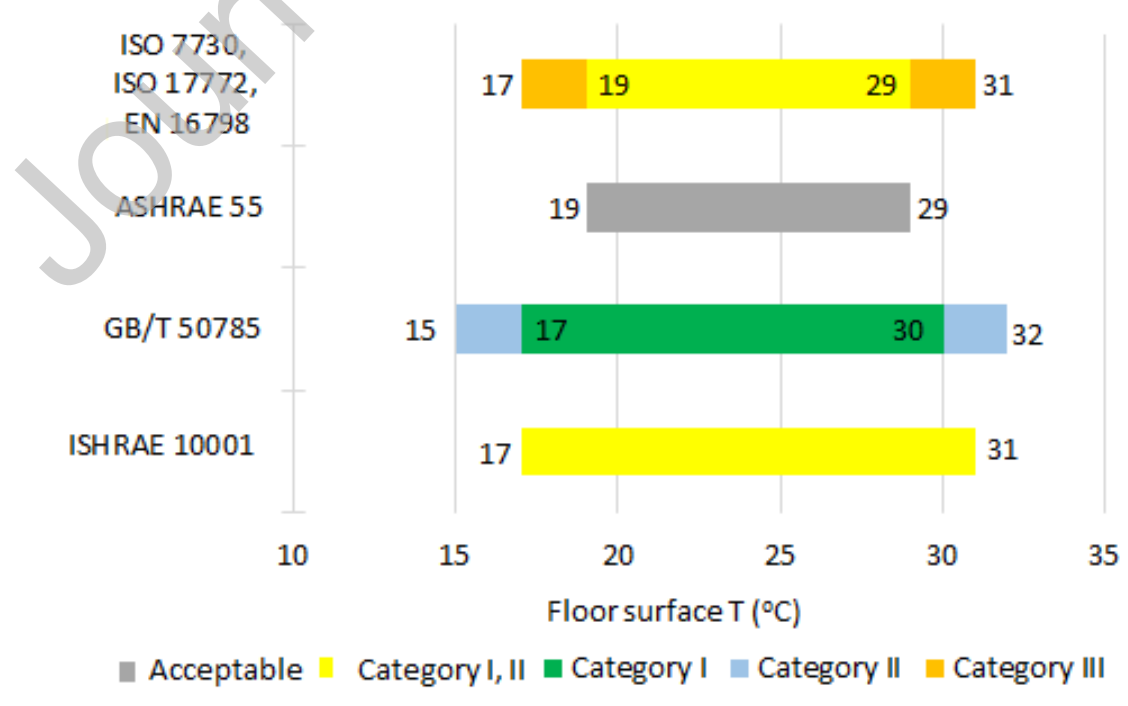

Figure 12: Acceptable temperature for warm or cool floors 


\subsubsection{Radiant temperature asymmetry}

Radiant temperature asymmetry is the difference between the plane radiant temperature in opposite directions measured at $0.6 \mathrm{~m}$ for a seated occupant and $1.1 \mathrm{~m}$ for a standing occupant. This asymmetry may cause local discomfort and reduce the thermal acceptability of space [8]. The criteria for radiant asymmetry are provided in Figure 8 as limits of PD and in Figure 13 as limits of acceptable temperature difference.

Generally, people are more sensitive to asymmetric radiation caused by a warm ceiling than that caused by hot and cold vertical surfaces. Acceptable limits of ASHRAE 55 are similar to ISO/EN standards Category I and II, while ISHRAE 10001 Category I is the same as ISO/EN Category III. The standard GB/T 50785 does not give criteria for radiant asymmetry. In ISHRAE 10001 no criteria are given for the percentage dissatisfied due to radiant asymmetry.

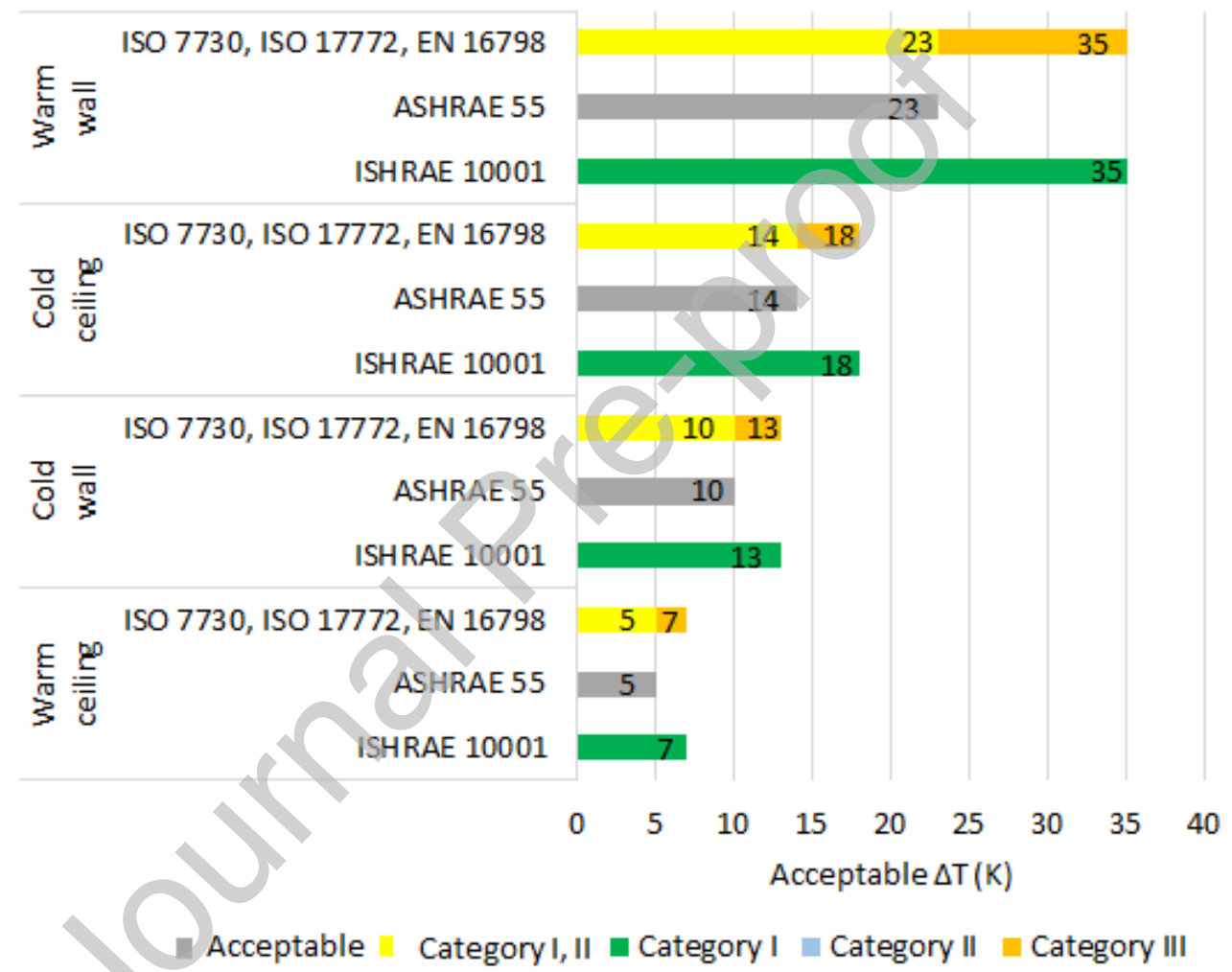

Figure 13: Acceptable temperature difference caused by radiant temperature asymmetry

\subsection{Non-steady state thermal environment}

ASHRAE 55 and ISO 7730 specify recommendations for cyclic variation and non-cyclic variations such as drift (passive monotonic change) and ramps (actively controlled monotonic change) of the operative temperature that are not caused by occupants but rather by operation of heating and cooling system.

ASHRAE 55 requires the peak-to-peak amplitude for cyclic variations of operative temperature to be no greater than $1.1^{\circ} \mathrm{C}$ with a period of less than $15 \mathrm{~min}$. For cyclic changes with a period greater than $15 \mathrm{~min}$ and for monotonic or non-cyclic changes, the operative temperature variation should not exceed the limiting values. For instance, the operative temperature change should not exceed $3.3^{\circ} \mathrm{C}$ over 4 hours, and 
at the same time the change should not be greater than $1.1^{\circ} \mathrm{C}$ each 15 min period within that longer interval of time.

ISO 7730 allows steady-state recommendations to be used for peak-to-peak variations in operative temperature to be up to $1 \mathrm{~K}$. Higher operative temperature variations can decrease comfort. Similarly, steady-state assumption is valid if the temperature change during drifts and ramps does not exceed $2 \mathrm{~K} / \mathrm{h}$. If the thermal environment does not stay within the specified ranges, it is considered transient. In a transient environment a step-change of temperature will be felt instantaneously. The new steady-state thermal sensation is experienced immediately after an up-step in operative temperature. Following a down-step in operative temperature, the thermal sensation does not change immediately. It drops at first to a level below the one predicted by PMV and then increases and reaches the steady-state level after approximately $30 \mathrm{~min}$ depending on the initial conditions [9].

\section{Ventilation for acceptable indoor air quality}

Indoor air quality (IAQ) is driven by health and comfort requirements and is affected by many parameters such as emissions from occupants (bio-effluent), emissions from activities and processes, and emissions from building materials and furnishing [5]. Requirements for residential and non-residential buildings are separated due to the different patterns of occupancy and activities. Standards that provide guidelines on IAQ include ISO 17772, EN 15251, EN 16798, ASHRAE 62.1 and 62.2, AS 1668.2, SS 553, SS 554 and ISHRAE 10001 (Table 7). While ASHRAE 62.1 and 62.2 provide recommendations on acceptable IAQ separately for non-residential (non-industrial) and residential buildings, the rest of the standards, except SS 553 and 554, describe ventilation requirements in a single document. In terms of non-residential spaces, this work focuses only on office spaces and classrooms for persons aged 5 and older.

Table 7: The scope of standards on indoor air quality

\begin{tabular}{l|c|c|c}
\hline \hline Standards & $\begin{array}{c}\text { Min. ventilation } \\
\text { rates per } \mathrm{m}^{2}\end{array}$ & $\begin{array}{c}\text { Max. allowed } \mathrm{CO}_{2} \\
\text { concentrations }\end{array}$ & Building type* \\
\hline \hline ISO 17772 & $\checkmark$ & $\checkmark$ & both \\
\hline EN 15251 & $\checkmark$ & $\checkmark$ & both \\
\hline EN 16798 & $\checkmark$ & $\checkmark$ & both \\
\hline ASHRAE 62.1 & $\checkmark$ & $\checkmark$ & non-residential \\
\hline ASHRAE 62.2 & $\checkmark$ & $\checkmark$ & residential \\
\hline AS 1668.2 & $\checkmark$ & $\mathbf{x}$ & both \\
\hline SS 553, SS 554 & $\checkmark$ & $\checkmark$ & non-residential \\
\hline ISHRAE 10001 & $\mathbf{x}$ & $\checkmark$ & both \\
\hline * residential or non-residential (offices and educational buildings)
\end{tabular}

\subsection{Requirements of percentage dissatisfied (PD)}

In ASHRAE 62.1, PD of $20 \%$ is acceptable according to the definition of acceptable indoor air quality as "air in which there are no known contaminants at harmful concentrations as determined by cognizant authorities and with which a substantial majority ( $80 \%$ or more) of the people exposed do not express dissatisfaction" [13]. Other standards specify different PD levels according to the category of IAQ, and their comparison is shown in Figure 14. Category I of the ISHRAE 10001 standard requires the lowest percentage $(10 \%)$ of dissatisfied with the air quality. ISO and EN standards allow $15 \%$ of PPD for the Category I. All 
standards aim for a PD of $20 \%$ in Category II, similarly to the acceptable level of ASHRAE standards. Per ISO and EN standards, the Category III allows $30 \%$ of dissatisfied occupants, and if PD exceeds $30 \%$ then the indoor environment is ranked as Category IV.

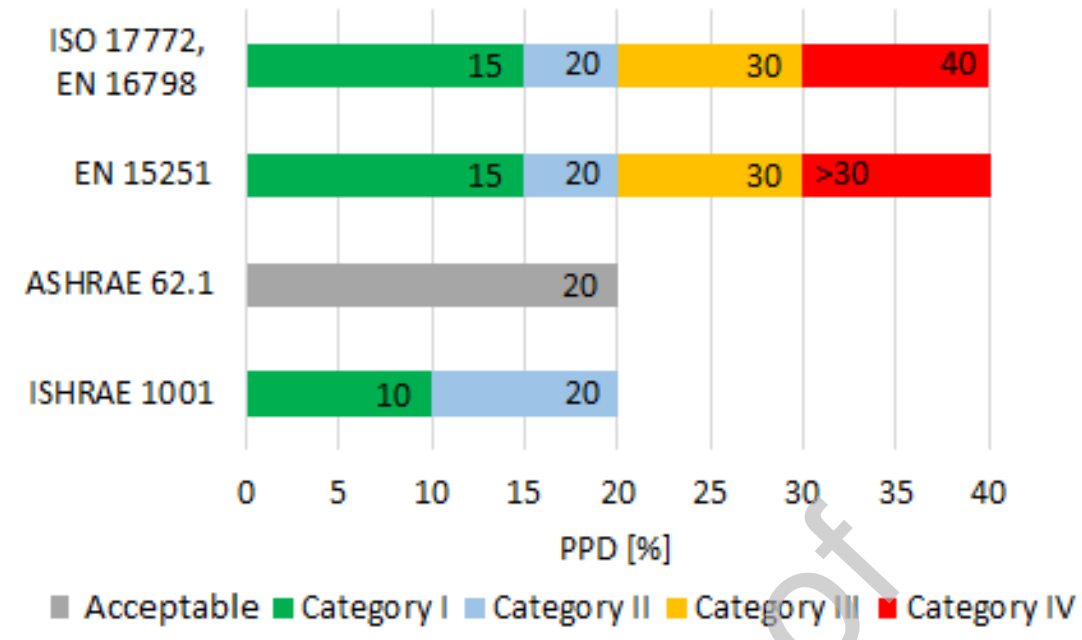

Figure 14: PPD requirements for indoor air quality

\subsection{Ventilation rate criteria for acceptable indoor air quality}

There is no common standard index that qualifies the indoor air quality as stated in ISO 17772 and EN 15251. However, the required ventilation rate and/or level of $\mathrm{CO}_{2}$ concentration is usually specified in standards as adequate IAQ criteria.

Minimum ventilation rates can be defined, according to ISO 17772 and EN 15251, using three methods:

- Perceived air quality (limit the odor level in the space perceived by the occupants)

- Limiting the concentration of specific contaminants

- Predefined ventilation flow rates based on occupation or floor area

Some methods are applicable either for only residential or non-residential buildings, while some methods are applicable for both types of buildings. Methods and parameters considered in each case are discussed in detail in the following subsections. The limiting ventilation rates specified in standards shall be used for designing mechanical, natural or hybrid ventilation systems. It is important to note that, according to ISO and EN standards, the total minimum air flow rate during occupancy should never be below $4 \mathrm{l} / \mathrm{s}$ per person due to health reasons [3]. According to the ASHRAE 62.1, minimum air flow in the breathing zone can be as low as $3.8 \mathrm{l} / \mathrm{s}$ for lecture halls, and $2.5 \mathrm{l} / \mathrm{s}$ for residential dwellings and office spaces (including conference and meeting rooms) [13].

\subsubsection{Definition of low- and very low polluting buildings}

Ventilation rates to control indoor emissions for non-residential buildings depend on the pollution level. Standards ISO 17772, EN 16798 and EN 15251 employ definitions of low polluting, very low polluted and non-low polluted buildings. The standards ISO 17772, EN 16798 refer to standards CEN/TS 16516 or ISO 1600 to define limits of different compounds in the air per building category, and it differs from the EN 15251 approach as shown in Table 8. 
Table 8: Definition of low polluting buildings and very low polluting buildings

\begin{tabular}{|c|c|c|c|c|}
\hline Standards & \multicolumn{2}{|c|}{ ISO 17772, EN 16798* } & \multicolumn{2}{|c|}{ EN 15251} \\
\hline Pollution level & Low & Very low & Low & Very low \\
\hline Emission rate & \multicolumn{2}{|c|}{$\mu \mathrm{gg} / \mathrm{m}^{3}$} & \multicolumn{2}{|c|}{$\mathrm{mg} /\left(\mathrm{m}^{2} * \mathrm{~h}\right)$} \\
\hline Total VOC (TVOC) & $<1000$ & $<300$ & $<0.2$ & $<0.1$ \\
\hline Formaldehyde & $<100$ & $<30$ & $<0.05$ & $<0.02$ \\
\hline Ammonia & -- & -- & $<0.03$ & $<0.01$ \\
\hline Carcinogenic VOC (class C1A or C1B) & $<5$ & $<5$ & -- & -- \\
\hline Carcinogenic compounds (IARC) & -- & -- & $<0.005$ & $<0.002$ \\
\hline Dissatisfaction with odor & -- & -- & $<15 \%$ & $<10 \%$ \\
\hline
\end{tabular}

* reference standards CEN/TS 16516, ISO 1600

\subsubsection{Ventilation rates based on perceived air quality}

Ventilation rates to limit the odor level perceived by people by removing both building emissions and bioeffluents are typically determined by summing contributions proportional to the number of occupants and to floor area as shown in Eqn. 4.

$$
q_{t o t}=N * q_{p}+A * q_{B}
$$

Ventilation rates to remove bioeffluents may be tabulated depending on the IEQ category and adaptation of occupants to odor from other people (Table 9). Occupants of high-density public spaces such as residential buildings, auditoria, classrooms, and cinemas easily get adapted to odor from bioeffluents [3], [4]. However, it does not mean that adapted occupants are not subject to fatigue and impaired concentration caused by the exposure to excessive concentration of bioeffluents in the air over a longer time. Standards ISO 17772 and EN 16798 specify ventilation rates per person for both adapted and nonadapted occupants, while ASHRAE 62.1 provides flow rates only for adapted occupants. As shown in Table 9, air flow required to remove bioeffluents is the highest for non-adapted occupants.

Table 9: Air flow rates for diluting emissions from occupants

\begin{tabular}{ll|cccc}
\hline \multirow{2}{*}{ Standard } & \multicolumn{4}{|c}{$\mathrm{q}_{\mathrm{p}}\left(\mathrm{I} / \mathrm{s}^{*}\right.$ person) } \\
\cline { 3 - 6 } & & Category I & Category II & Category III & Category IV \\
\hline \hline \multirow{2}{*}{ ISO 17772, } & adapted $^{\mathrm{a}}$ & 3.5 & 2.5 & 1.5 & 1 \\
\cline { 2 - 6 } EN 16798 & non-adapted & 10 & 7 & 4 & 2.5 \\
\hline EN 15251 & (non-adapted) & 10 & 7 & 4 & $<4$ \\
\hline ASHRAE 62.1 & (adapted) & \multicolumn{2}{|c|}{2.5 (offices), 3.8 (lecture auditoria), 5 (classrooms, age 5+) } \\
\hline \hline
\end{tabular}

a - although the min. air flow rates are less than $4 \mathrm{l} / \mathrm{s}$, the recommended minimum ventilation rate of $4 \mathrm{l} / \mathrm{s}$ per person should be applied throughout all categories due to health reasons [3]

Ventilation rates to remove emissions from buildings depend on the IEQ category and on the pollution level for non-residential buildings as shown in

Table 10 and Table 11. For non-residential buildings, ISO 17772, EN 16798 and EN 15251 have similar requirements for ventilation rates, but EN 15251 does not specify any values for Category IV. Therefore, 
any ventilation rates below values specified for Category III are considered to be Category IV. For residential buildings, acceptable ventilation rate due to building components per ASHRAE 62.2 is at the same level as requirements for Category II of standards ISO 17772 and EN 16798.

Table 10: Air flow rates for diluting emissions due to the building component in non-residential zones

\begin{tabular}{|c|c|c|c|c|c|c|c|c|c|c|c|c|}
\hline \multirow{3}{*}{$\begin{array}{l}\text { Standard } \\
\text { Category }\end{array}$} & \multicolumn{12}{|c|}{$\mathrm{q}_{\mathrm{b}}\left(\mathrm{l} / \mathrm{s}^{*} \mathrm{~m}^{2}\right)$} \\
\hline & \multicolumn{4}{|c|}{ Very low polluted } & \multicolumn{4}{|c|}{ Low polluted } & \multicolumn{4}{|c|}{ Non-low polluted } \\
\hline & 1 & II & III & IV & I & II & III & IV & 1 & II & III & IV \\
\hline $\begin{array}{l}\text { ISO } 17772^{a} \text {, } \\
\text { EN } 16798\end{array}$ & 0.5 & 0.35 & 0.3 & 0.25 & 1 & 0.7 & 0.4 & 0.3 & 2 & 1.4 & 0.8 & 0.6 \\
\hline EN 15251 & 0.5 & 0.35 & 0.3 & -- & 1 & 0.7 & 0.4 & -- & 2 & 1.4 & 0.8 & -- \\
\hline ASHRAE 62.1 & \multicolumn{12}{|c|}{0.3 (offices, auditoria), 0.6 (classrooms, age $5+$ ) } \\
\hline
\end{tabular}

Table 11: Air flow rates for diluting emissions due to the building component in residential buildings

\begin{tabular}{lccc}
\hline \hline \multirow{2}{*}{ Standard } & \multicolumn{3}{c}{$\mathrm{q}_{\mathrm{b}}\left(\mathrm{I} / \mathrm{s}^{*} \mathrm{~m}^{2}\right)$} \\
\cline { 2 - 4 } & Category I & Category II & Category III \\
\hline \hline ISO 17772, EN 16798 & 0.25 & 0.15 & 0.1 \\
\hline ASHRAE 62.2 & \multicolumn{3}{c}{0.15 (acceptable level) } \\
\hline \hline
\end{tabular}

A comparison of ventilation rates of different standards according to the perceived air quality method is shown in Figure 15. Requirements for offices, conference rooms, and classrooms are shown separately due to the difference in occupation:

- For offices, both single and open space, the default occupant density is $10 \mathrm{~m}^{2} /$ person for a single office, $15 \mathrm{~m}^{2} /$ person for a landscaped office according to EN 15251 and EN 16798. Per ASHRAE 62.1 , the default occupant density is $20 \mathrm{~m}^{2} /$ person for office spaces. In order to be able to compare the ventilation requirements from different standards, an occupant density of $10 \mathrm{~m}^{2} /$ person was used for calculations.

- For conference rooms and classrooms, an occupant density of $2 \mathrm{~m}^{2}$ per person is suggested per EN 15251, EN 16798 and ASHRAE 62.1. ASHRAE 62.1 suggested using $4 \mathrm{~m}^{2}$ per person for ages 5-8 and $2.86 \mathrm{~m}^{2}$ per person for ages 9 and above. For the comparison of ventilation rates across standards, the occupant density of $2 \mathrm{~m}^{2}$ per person was used.

Ventilation rate according to standards ISO 17772, EN 16798 and EN 15251 depend on the category of indoor air and the pollution level. Generally, ISO 17772, EN 16798 and EN 15251 have the same ventilation rate requirements for Categories I-III. No requirements are provided for the Category IV in EN 15251, therefore no results are shown. ISO 17772 and EN 16798 specify values for the Category IV as 1.4, 1.6 and $1.9 \mathrm{~L} / \mathrm{s}$ per $\mathrm{m}^{2}$ for very low-polluting, low-polluting and non-low polluting zones, respectively. It is important to note that ISO 17772 and EN 16798 recommend ventilation rates to never be lower than $4 \mathrm{~L} / \mathrm{s}$ per person which is equal to $2 \mathrm{~L} / \mathrm{s}$ per $\mathrm{m}^{2}$, but ASHRAE 62.1 does not have a requirement of minimum $4 \mathrm{~L} / \mathrm{s}$ per person and provides only acceptable level of the ventilation rate. 
(a) offices

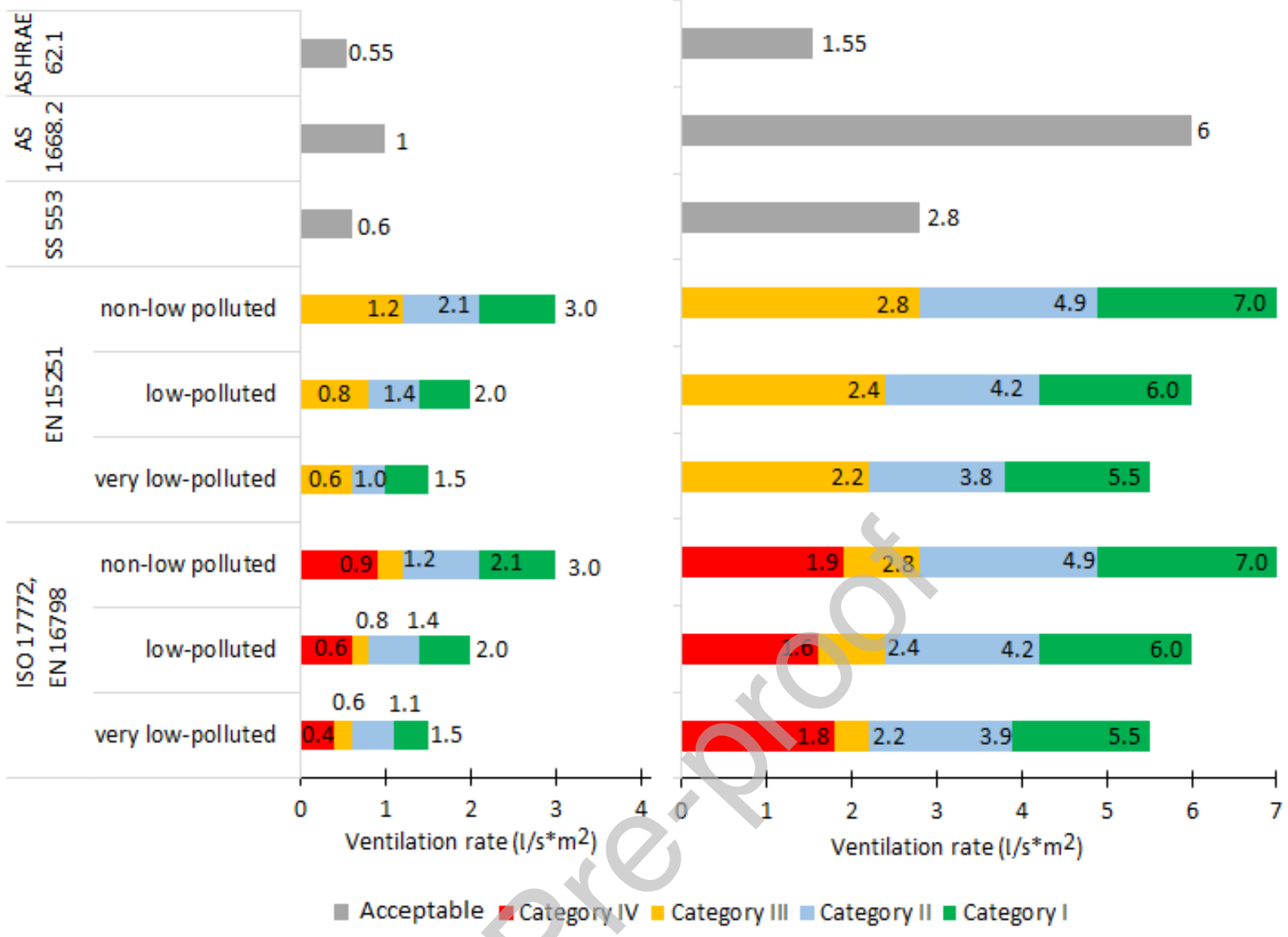

Figure 15: Requirements for total ventilation rates: (a) offices, (b) conference rooms and classrooms

\subsubsection{Ventilation rates based on the limitation of specific contaminants}

Standards such as ISO 17772, EN 16798, EN 15251, ASHRAE 62.1 and ISHRAE 10001 describe calculation methods for ventilation flow rate and/or give maximum values for common indoor pollutants. For example, the indoor concentration of $\mathrm{CO}_{2}$ above the outdoor level is widely used to evaluate perceived air quality (comfort), since $\mathrm{CO}_{2}$ can be used as a tracer of occupants' presence. ISO 17772, EN 16798, EN 15251, ASHRAE 62.1 and ISHRAE 10001 give recommendations shown in Figure 16 for maximum $\mathrm{CO}_{2}$ concentrations above ambient.

According to EN 16798, if the concentration of an external pollutant is lower than indoors, ventilation flow rate to dilute individual substances such as $\mathrm{CO}_{2}$, formaldehyde, VOCs, etc., can be defined by a steady state mass balance:

$$
Q_{h}=\frac{G_{h}}{C_{h, i}-C_{h, o}} * \frac{1}{\varepsilon_{v}}
$$

In this method, unlike the one discussed in the previous Section 3.2.2, the emission from building materials is not required to be known. This can be an advantage, since the exact choice of materials in buildings may not be decided until the very late stage in the building design. However, this can also be a disadvantage, since the emission from building materials is not considered at all.

AS 1668.2 mentions that typical set points for $\mathrm{CO}_{2}$ concentration are $600-800 \mathrm{ppm}$ and should be selected based on the ambient level of the site and the enclosure characteristics. Perhaps, if the $\mathrm{CO}_{2}$ level outdoors 
is relatively low the lower limit applies, and if it is relatively high the upper limit applies; therefore, no standardized criteria for allowed $\mathrm{CO}_{2}$ concentration are presented. SS 554 specifies that an acceptable limit to be $700 \mathrm{ppm}$ above the outdoor level. ASHRAE 62.1 discusses the use of indoor $\mathrm{CO}_{2}$ levels to indicate ventilation rate, for example, if the ventilation rate is $7.5 \mathrm{l} / \mathrm{s}$-person then steady-state $\mathrm{CO}_{2}$ should be 700 ppm above outdoor air levels in order for the substantial majority of occupants to be satisfied with the indoor body odor. However, ASHRAE 62.1 currently does not provide any specific limiting numbers, but it permits and discusses dynamic ventilation, which can be controlled by $\mathrm{CO}_{2}$. The rest of the standards (ISO 17772, EN 16798, EN 15251, ISHRAE 10001) provide specific limiting concentrations for different IEQ categories as shown in Figure 16. EN 15251 and ISHRAE 10001 require the same $\mathrm{CO}_{2}$ concentration levels per each category. The acceptable level for the Category I according to ISO 17772 and EN 16798 is 550 ppm, which is 200 ppm higher than in EN 15251 and ISHRAE 10001 standards, and Category II is the same as Category III in abovementioned standards. Therefore, EN 15251 and ISHRAE 10001 have the strictest ranges of acceptable $\mathrm{CO}_{2}$ concentrations per category.

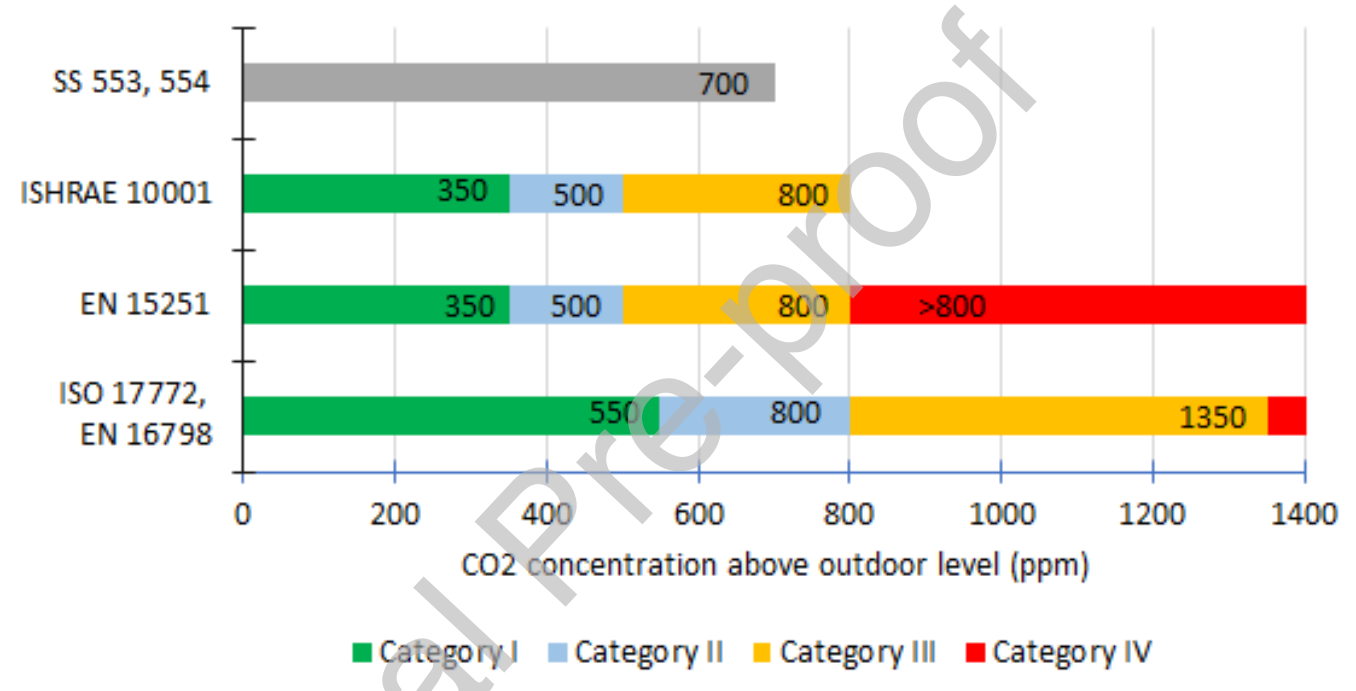

Figure 16: Acceptable CO2 concentrations for non-residential buildings

In terms of acceptable concentration of other chemicals, ISO 17772, EN 15251 and EN 16798 specify limiting values of contaminants recommended by the World Health Organization (WHO) which issues nonmandatory guidelines. The values are listed in Table 12. ISHRAE 10001 does not refer to the WHO as the primary source, but its requirements are within the limits of the WHO for all components. ASHRAE 62.1 provides an explicit table with acceptable concentrations of contaminants from different organizations, only enforceable and regulatory levels are presented in Table 12. According to EN 15251, detection of specific pollutants such as formaldehyde, other VOCs, fine dust (MP10, PM2.5) should be performed if the requirements for fresh air supply are met but the specific smell and SBS complaints persist.

Table 12: Maximum indoor contaminant exposure according to WHO and ISH 10001

\begin{tabular}{c|c|c|c|c|c|c|c}
\hline Standard & Ref. & $\begin{array}{c}\text { Carbon } \\
\text { monoxide } \\
\mathrm{CO},(\mathrm{ppm})\end{array}$ & $\begin{array}{c}\mathrm{TVOC}, \\
\left(\mu \mathrm{g} / \mathrm{m}^{3}\right)\end{array}$ & $\begin{array}{c}\text { Formaldehyde } \\
\mathrm{CH}_{2} \mathrm{O},\left(\mu \mathrm{g} / \mathrm{m}^{3}\right)\end{array}$ & $\begin{array}{c}\mathrm{SO}_{2,} \\
\left(\mu \mathrm{g} / \mathrm{m}^{3}\right)\end{array}$ & $\begin{array}{c}\mathrm{NO}_{2,} \\
\left(\mu \mathrm{g} / \mathrm{m}^{3}\right)\end{array}$ & $\begin{array}{c}\text { Ozone } \mathrm{O}_{3,} \\
\left(\mu \mathrm{g} / \mathrm{m}^{3}\right)\end{array}$ \\
\hline \hline WHO & -- & $\begin{array}{c}90[15 \mathrm{~min}], \\
50[30 \mathrm{~min}], \\
25[1 \mathrm{~h}], \\
\end{array}$ & -- & $100[30 \mathrm{~min}]$ & $\begin{array}{c}135[24 \mathrm{~h}], \\
34[1 \mathrm{yr}]\end{array}$ & $\begin{array}{c}203[1 \mathrm{~h}], \\
40.5[1 \mathrm{yr}]\end{array}$ & $120[8 \mathrm{~h}]$ \\
& & & & & & \\
\hline
\end{tabular}




\begin{tabular}{|c|c|c|c|c|c|c|c|}
\hline \multirow{3}{*}{$\begin{array}{c}\text { ISHRAE } \\
10001\end{array}$} & Class A & 9 & 200 & 30 & 40 & 40 & 50 \\
\hline & Class B & 9 & 400 & 100 & 80 & 80 & 100 \\
\hline & Class C & 9 & 600 & -- & -- & -- & -- \\
\hline \multirow[t]{3}{*}{$\begin{array}{c}\text { ASHRAE } \\
62.1\end{array}$} & $\begin{array}{l}\text { NAAQA/ } \\
\text { EPA }^{a}\end{array}$ & $\begin{array}{c}9 \text { [once per } \\
\text { year], } \\
35[1 \mathrm{~h}]\end{array}$ & \multirow{3}{*}{$\begin{array}{c}\text { Precise } \\
\text { level } \\
\text { cannot } \\
\text { be given }^{\mathrm{e}}\end{array}$} & -- & $\begin{array}{l}0.03[1 \mathrm{yr}] \\
0.14[24 \mathrm{~h}]\end{array}$ & $0.05[1 \mathrm{yr}]$ & $\begin{array}{c}0.12[1 \mathrm{~h}] \\
0.08\end{array}$ \\
\hline & $\mathrm{OSHA}^{\mathrm{b}}$ & 50 & & $\begin{array}{c}0.75 \\
2[15 \mathrm{~min}]\end{array}$ & 5 & 5 [ceiling] & 0.1 \\
\hline & MAK $^{\mathrm{c}}$ & $\begin{array}{c}30, \\
60[30 \mathrm{~min}]\end{array}$ & & $0.3,1^{d}$ & $0.5,1^{d}$ & $\begin{array}{c}5, \\
10[5 \mathrm{~min}]\end{array}$ & $\begin{array}{c}\text { Carci- } \\
\text { rogenic }\end{array}$ \\
\hline
\end{tabular}

${ }^{a}$ National Ambient Air Quality Standards/Environmental Protection Agency (USA), ${ }^{b}$ Occupational Safety and Health Administration (USA), 'Commission for the Investigation of Health Hazards of Chemical Compounds in the Work Area, Federal Republic of Germany, ${ }^{d}$ never to be exceeded, ${ }^{e}$ setting target levels for specific VOCs of concern is suggested

\subsubsection{Prescriptive ventilation rates}

This method provides required ventilation rates as pre-defined rates expressed, according to ISO 17772 , by one or more parameters such as:

- Total design ventilation for people and building component

- Design ventilation per number of occupants ( $1 / \mathrm{s}$ per person), including dilution of both emission from people and materials.

- Design ventilation per floor area $\left(\mathrm{l} / \mathrm{s}-\mathrm{m}^{2}\right)$, including dilution of both emission from people and materials.

- Design air change rates

- Design air flow rates per room and building type.

If ventilation rates per occupant and floor area are known, as indicated in EN 15251, different options of defining required ventilation rate are possible: (1) the sum of two values, (2) only the highest of the two values, (3) the value between the highest number and the value based on addition. A designer should decide which value is appropriate if no additional national regulations are imposed. If the total design ventilation or the sum of ventilation rates per occupants and per floor area are used, then this method is identical to method 1 (based on perceived air quality).

This method has the advantage of defining ventilation rates in residential buildings where ventilation is defined based on the number of people or bedrooms, an example of the recommended ventilation rates in residential buildings per ASHRAE 62.2 is shown in Figure 17. ISO 17772 specifies that supply air flow per person in residential buildings should be $10 \mathrm{l} / \mathrm{s}$-person for Category I, $7 \mathrm{l} / \mathrm{s}$-person for Category II, and $4 \mathrm{l} / \mathrm{s}$ person for Category III. 


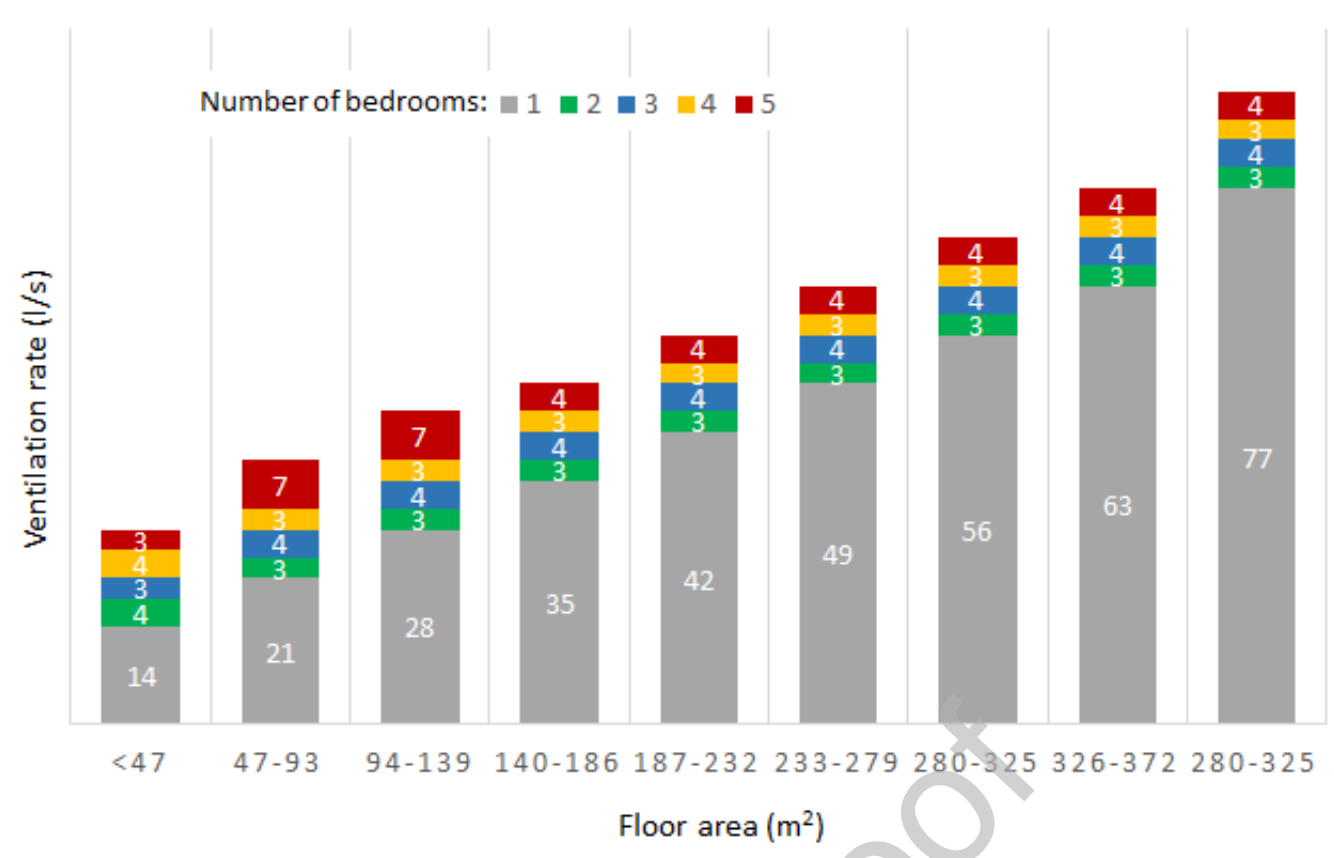

Figure 17: Recommended ventilation rates in residential buildings

\subsubsection{Dynamic ventilation, ventilation during un-occupied hours}

Methods described in chapters 3.2.2-3.2.4 define required ventilation rates based on the maximum occupation of a particular space. In reality, the occupancy of rooms varies dynamically from maximum, at full occupation, to a minimum when space is unoccupied. Therefore, modulation of the supply air rate (demand-controlled ventilation) can aid to reduce the required ventilation rate in response to the actual population of the building.

Demand controlled ventilation is permitted by all the standards with some restrictions. In EN 16798, the ventilation rate may vary between maximum and minimum depending on the occupancy and pollution load or moisture level. According to AS 1668.2, the occupancy-based outdoor air supply may be reduced in accordance with actual occupancy, but not below the minimum area-based outdoor air ventilation rate of $0.35 \mathrm{l} / \mathrm{s}-\mathrm{m}^{2}$.

In addition to the requirements for the design and dynamic ventilation rates, requirements for ventilation rates during unoccupied hours are the following:

- EN 15251 requires outdoor air supply from 0.1 to $0.2 \mathrm{~L} / \mathrm{s}-\mathrm{m}^{2}$ during un-occupied hours in nonresidential buildings, if national recommendations are not available. Delivery of two fresh air volumes before occupancy should be assured.

- ISO 17772 and EN 16798 provide recommendations for ventilation of building components during unoccupied hours. Additionally, rooms should be ventilated with minimum of $0.15 \mathrm{~L} / \mathrm{s}$ per $\mathrm{m}^{2}$ during un-occupied hours and prior to occupation one volume of fresh air within two hours should be delivered.

- In ASHRAE 62.1, required ventilation rates outside of the expected occupancy period are not provided. However, ventilation can be reduced to zero in the occupied-standby mode in common areas such as conference rooms, lecture halls, corridors, main entry lobbies, and reception areas.

- Ventilation outside occupied hours is not mentioned in ISHRAE 10001.

- AS 1668.2 describes that it is acceptable to turn off the ventilation during un-occupied hours, and states that ventilation may be required before and after occupancy but does not specify the amount of ventilation necessary. 


\subsubsection{Natural ventilation}

Some standards give recommendations for natural ventilation in terms of required opening areas such as operable windows even if mechanical ventilation is in use. AS 1668.2 and ASHRAE 62.1 give guidelines on how to use natural ventilation in non-residential buildings.

ASHRAE 62.1 requires that a natural ventilation system should be complemented with a mechanical ventilation system except in the following cases:

- for zones not mechanically cooled or heated

- for zones having permanently open openings or openings with controls that prevent them from being closed during periods of expected occupancy

- $\quad$ engineered natural ventilation system approved by an authority with jurisdiction.

\subsubsection{Outdoor air quality, filtration and air cleaning}

Outdoor air must be of suitable quality to be used for ventilation. According to ASHRAE 62.1 and ISO 17772, outdoor air with special attention to ozone and the particulate matter should be investigated around the building site prior to design of the ventilation system. AS 1668.2 specifies values for maximum acceptable concentrations of some contaminants in outdoor air adopted by the Australian National Environment Protection Council (NEPC). ASHRAE 62.1 requires investigation of whether air quality meets regional standards, e.g., the National Ambient Air Quality Standards in the United States. The rest of the standards specify requirements for filtration and air cleaning as control of outdoor air pollutions. Standards ISO 17772, EN 15251 and EN 16798 mainly refer to other standards for more information on filters and air cleaning, while AS 1668.2 and ASHRAE 62.1 provide an in-depth description of the filtration requirements. General requirements for filtration and air cleaning from different standards are given in Table 13.

Table 13: Requirements for filtration and air cleaning

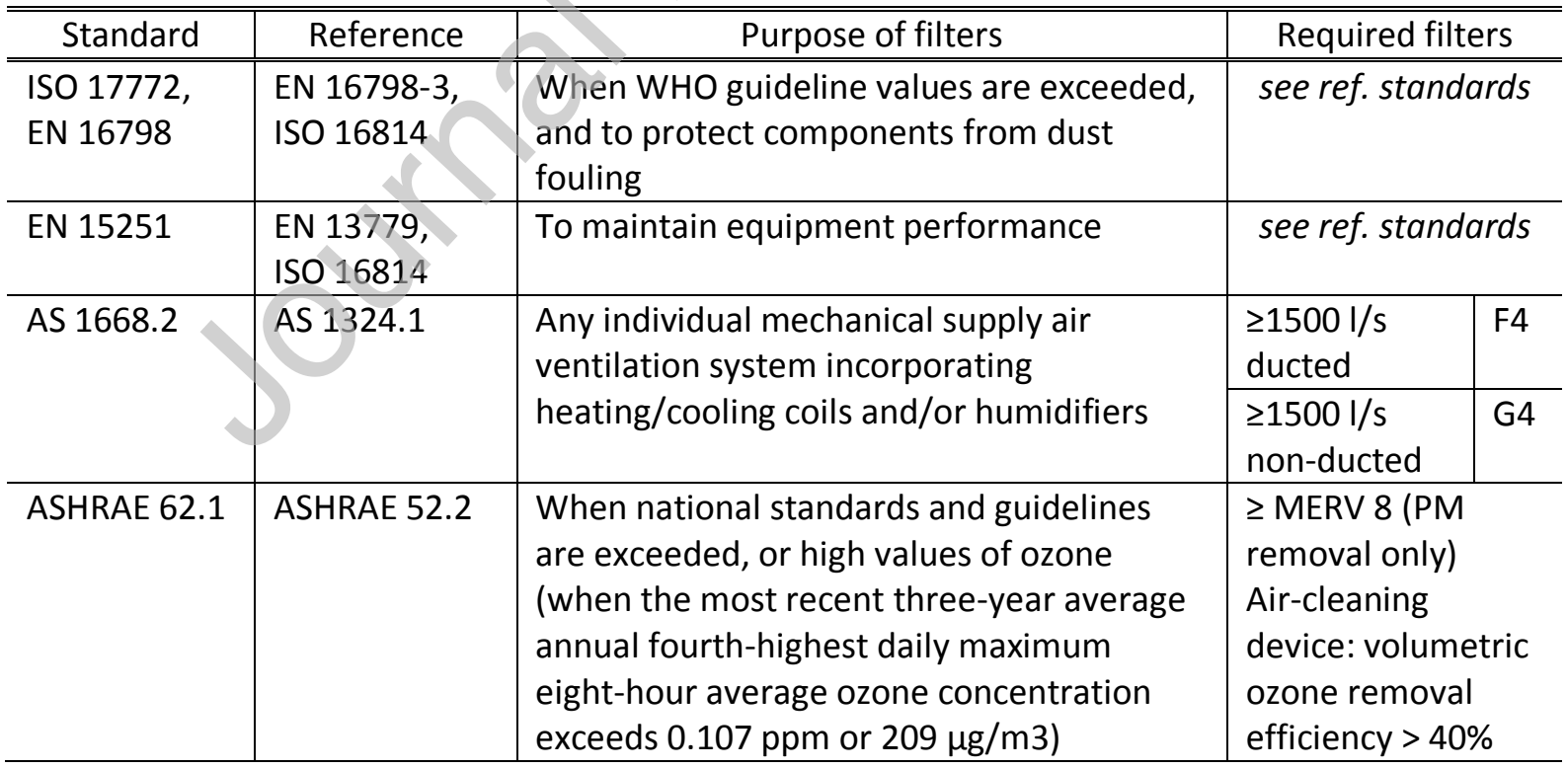

\subsubsection{Recirculation}

AS 1668.2 and ASHRAE 62.1 provide recommendations for the use of recirculated air. AS 1668.2 states that similar occupancies may be served by common recirculation systems, and air handling systems shall not recycle air to dissimilar occupancies except when the recycle air is treated in an acceptable manner. AS 
1668.2 also requires that air from an enclosure ventilated by a required general or local exhaust system shall not be recycled to other enclosures of different use. ASHRAE 62.1 allows recirculation if the ventilation rate procedure is used. The recirculation of air is, however, limited by the classification of the air leaving several types of rooms. The air can be assigned to a cleaner class in some cases if it has passed through an air cleaning system or is sufficiently diluted with the air of a higher class.

\subsection{Humidity limits}

According to all standards reviewed, absolute humidity should be kept below $12 \mathrm{~g} / \mathrm{kg}$, even if no dehumidification is used. In terms of relative humidity, standards provide recommended ranges shown in Figure 18 when humidification/dehumidification is used. ISO 17772, EN 16798 and EN 15251 require relative humidity to be maintained within $30-50 \%$ for Category I, $25-60 \%$ for Category II, and $20-70 \%$ for Category III. No criteria for the relative humidity for Category IV are stated meaning that any values beyond limits of the Category III are unacceptable. ASHRAE 62.1 requires using mechanical air-conditioning systems with dehumidification to keep relative humidity limited to $65 \%$ in the occupied spaces unless process or occupancy dictates higher humidity conditions. There is no lower limit for the humidity. The maximum relative humidity recommended by ASHRAE 55 is between the recommendations for the Category II and III according to ISO and EN standards. ISHRAE 10001 requires relative humidity to be in the range between $20 \%$ and $70 \%$ which is equal to ISO and EN standards Category III.

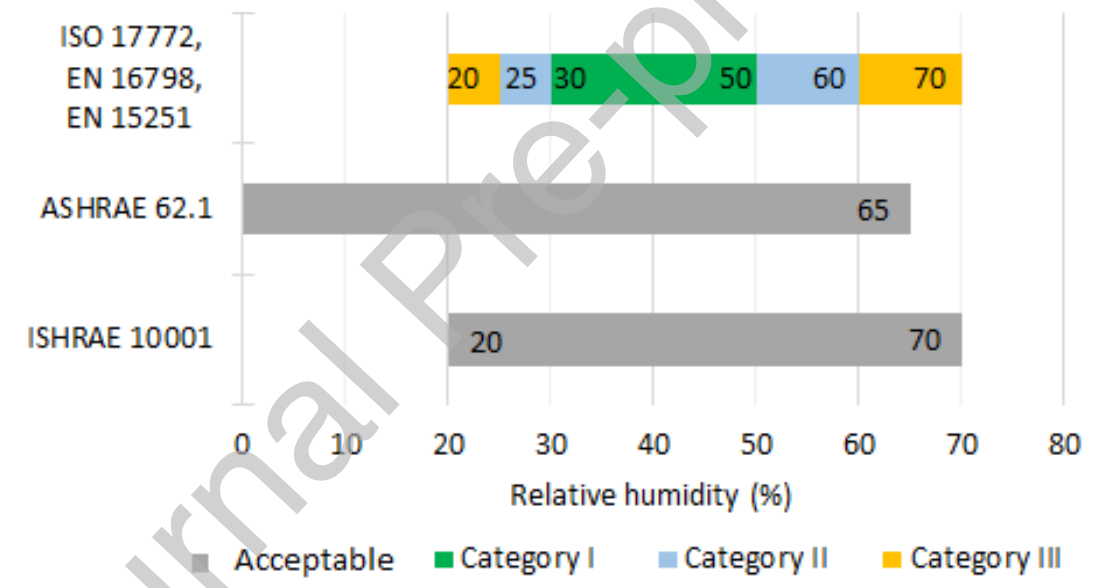

Figure 18: Recommended relative humidity ranges 


\section{IEQ exceedance acceptability}

Standards provide requirements on how much time an IEQ parameter can be outside the limits for a category while still complying with the requirements to the category. Most of the standards specify the percentage of the building area within a given range of IEQ parameters and accepted time outside the range. The accepted exceedance is shown in Table 14.

Table 14: Accepted deviations from the standard

\begin{tabular}{|c|c|c|}
\hline Standard & Accepted exceedance hours & $\begin{array}{l}\text { Part of the building required to be } \\
\text { within ranges }\end{array}$ \\
\hline $\begin{array}{l}\text { ISO 17772, } \\
\text { EN } 16798\end{array}$ & $\begin{array}{l}\text { Weekly: } 20 \% \text { or } 50 \% \\
\text { Monthly: } 12 \% \text { or } 25 \% \\
\text { Yearly: } 3 \% \text { or } 6 \%{ }^{a}\end{array}$ & $\begin{array}{l}\text { Rooms representing } 95 \% \text { of } \\
\text { building volume }\end{array}$ \\
\hline EN 15251 & $\begin{array}{l}\text { Hourly, daily, weekly, } \\
\text { monthly, yearly: } 3 \% \text { or } 5 \% \text { a,b }\end{array}$ & $\begin{array}{l}\text { Floor area-weighted average for } \\
95 \% \text { of the building space }\end{array}$ \\
\hline ASHRAE 55 & $\begin{array}{l}\text { Design exceedance hours } \\
\text { shall be documented }\end{array}$ & $\begin{array}{l}\text { Any space where the standard is } \\
\text { not applied shall be identified }\end{array}$ \\
\hline GB/T 50785 & -- & $90 \%$ of main function rooms \\
\hline
\end{tabular}

${ }^{a}$ Recommended value if national regulations do not specify otherwise

${ }^{\mathrm{b}}$ No exceedance for lighting criteria

Standards ISO 17772 and EN 16798 provide different recommended exceedance periods for weeks, months and one year. This allows setting indirect criteria for how long consecutive periods can last outside the given ranges. A high weekly accepted exceedance period with a low yearly exceedance period will for instance open for one very hot week. A low weekly exceedance period will allow for some exceedance every week throughout the year. ISO 17772 and EN 16798 state that acceptable exceedance hours are given to allow for variations in the actual weather compared to the weather files used during simulations and to avoid too large building systems that will run with reduced capacity most of the year.

The standard EN 15251 allows identical hourly, daily, weekly, monthly and yearly exceptions outside the required ranges, while ASHRAE 55 does not provide values on how much time the recommended ranges can be exceeded, but states that it shall be documented if the ranges are designed to be exceeded.

ISO 17772, EN 16798 and EN 15251 recommend that at least 95\% of the building is within the recommended ranges within a certain category to be classified as belonging to this Category. GB/T 50785 recommends that $90 \%$ of the main rooms in the building are within the ranges of the given class to be categorized as belonging to this class. ASHRAE 55 specifies how to determine exceedance hour, however it does not state a limit for the total number of exceedance hours. ISHRAE 10001 does not mention acceptable deviations but describes when, how and where to measure the IEQ to make sure that it is representative. Standards SS and AS do not provide any exceedance acceptability. 


\section{Long term evaluation of the indoor environment}

ISO 7730, ISO 17772, EN 16798, EN 15251 and ASHRAE 55 describe different methods for long term evaluation of the indoor environment (Table 15). The methods are labeled from $A$ to $E$ :

- Method A: percentage outside the range: calculation of the number or percentage of occupied hours when the PMV or the operative temperature is outside a specified range.

- Method B: degree hours criteria: weighted exceedance based on how many degrees the range has been exceeded.

- $\quad$ Method C: PPD weighted criteria - weighted exceedance based on the PPD in the hours where the range has been exceeded.

- Method D: Calculating the average PPD over the occupied hours

- Method E: Summing the PPD over the occupied hours.

Table 15: Methods described for long term evaluation of the indoor environment for different standards

\begin{tabular}{l|c|c|c|c|c}
\hline \hline \multirow{2}{*}{ Standard } & \multicolumn{5}{|c}{ Method } \\
\cline { 2 - 6 } & A & B & C & D & E \\
\hline \hline ISO 7730 & $\checkmark$ & $\checkmark$ & $\checkmark$ & $\checkmark$ & $\checkmark$ \\
\hline ISO 17772 & $\checkmark$ & $\checkmark$ & $\checkmark$ & $\mathbf{x}$ & $\mathbf{x}$ \\
\hline EN 16798 & $\checkmark$ & $\checkmark$ & $\checkmark$ & $\mathbf{x}$ \\
\hline EN 15251 & $\checkmark$ & $\checkmark$ & $\mathbf{x}$ & $\mathbf{x}$ & $\mathbf{x}$ \\
\hline ASHRAE 55 & $\checkmark$ & $\mathbf{x}$ & & $\mathbf{x}$ \\
\hline
\end{tabular}

ISO 7730 describes all 5 methods; ISO 17772, EN 16798 and EN 15251 describe methods A, B and C, and ASHRAE 55 describes method A. The different methods of calculating exceedance hours give a different number of exceedance hours.

Some of the standards do not give values for how much of the building should be considered when making long term evaluation of the indoor environment or how much time the recommended ranges can be exceeded, but give recommendations for when and where measurements should be taken to classify the building.

AS 1668.2 does not give recommendations for how much of the time the indoor environment can be outside the recommended ranges but gives a figure showing the accepted lag time between increase in occupancy and adjustment in outdoor air flow. At the same time, the standard requires that the contaminants shall not exceed acceptable levels during occupied hours.

GB/T 50785 requires that measurements shall be carried out when the temperature difference between indoor and outdoor is no less than $50 \%$ of the design temperature difference when evaluating the indoor environment. This opens up for the temperature being out of the recommended ranges during the design stage. The standard also recommends that the least favorable measurement set taken in a measurement period of 24-48 hours with 30 min intervals be used.

ISHRAE 10001 recommends that measurement sampling shall be representative of locations where the occupants are known to or expected to, spend their time. Locations, where the most extreme values are observed or estimated to occur, shall be included in the measurements. 


\section{Discussion}

The critical analysis of thermal comfort and IAQ-related standards reveals strong similarities between the numerical ranges of categories across standards. This is no doubt due to the fact that the regional standards are influenced by the "international" standards, that are based on the same pool of research conducted mostly in the US and Europe. However, regional differences in climate, building typology, etc., might have a significant influence on the perception of the occupants as it is illustrated for the adaptive model applicable to China. As a result, this calls into question the applicability - and feasibility - of international standards. It would be more appropriate for individual countries to use the concepts provided in standards such as EN and ISO and set "local" limiting values considering particular specifics of the region.

In addition, most of the standards provide recommendations for various categories of IEQ by specifying the predicted percentage of dissatisfied occupants (PPD) associated with the certain level, as shown in Figure 19 for thermal comfort and air quality across standards, or by stating limiting values for certain IEQ parameters. In other words, IEQ standards focus on perception rather than productivity and wellness as quantitative criteria. For example, ASHRAE standards, ISHRAE Category I and GB/T 50785 Category I aim for the same level as to ISO and EN standards Category II, with $10 \%$ dissatisfied with the overall thermal environment and $20 \%$ dissatisfied with the indoor air quality. GB/T Class II aims for the same amount of dissatisfied (25\%) with the overall thermal comfort as ISO 17772 and EN 16798 Category IV. Even though the standards are designed with an aim for the same comfort level, parameter recommendations vary slightly between them. Both ASHRAE 55 and GB/T 50785 Class I recommend higher operative temperatures than the ISO and EN standards Category II, even though they aim for the same number of dissatisfied. GB/T 50798 Category II also recommends higher temperatures than ISO 17772 and EN 16798 Category IV. The standards providing recommendations for ventilation rates specify different methods of determining ventilation rates, which results in different recommendations for ventilation rate requirements. Generally, differences between standards may reflect differences in the priorities of those who write them. For instance, minimum ventilation rates are lower in ASHRAE 62.1 than in EN 15251 largely because the ASHRAE 62.1 committee decided that adapted ventilation rates were acceptable while the committee responsible for EN 15251 opted for higher unadapted rates.

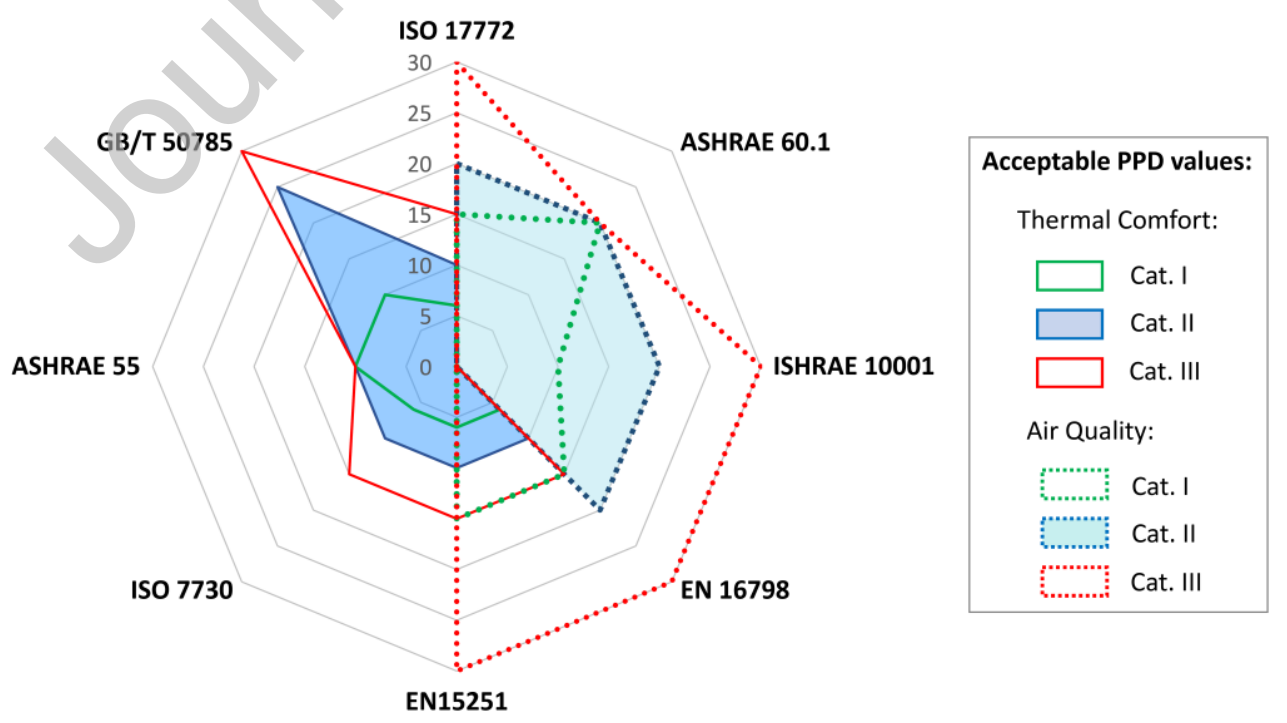

Figure 19: Overview of PPD values related to thermal comfort and air quality across various standards 
It is necessary to mention that the differences in the recommendations per category suggested by different standards can have an effect on the operation and energy use of the different types of buildings. Therefore, it would be advantageous to conduct a parametric study on the energy use of residential and nonresidential environments based on the different IEQ recommendations according to various standards.

The review shows that standards treat IEQ factors such as thermal comfort and air quality individually, however, there is a need for a method to combine various indoor environmental factors to a combined indicator similarly to how the energy performance of buildings is evaluated with one value like primary energy use in kWh/year. Therefore, the weighting of different IEQ dimensions such as thermal, air quality, light, and sound correctly into a composite score would be a major advance in the future. In order to do it, sufficient data on the overall impact on perception, health, performance, or other appropriate global metrics are required because standards as applied continue to focus primarily on perceived environmental quality.

\section{Conclusions}

An extensive review of IEQ-related standards focusing on thermal comfort and indoor air quality is presented in this work. While standards such as ISO 17772, EN 15251, EN 16798, ISHRAE 10001 focus on both IEQ categories, standards such as ISO EN 7730, ASHRAE 55, GB/T 50785, SS 553 provide only recommendations for thermal environment, and standards such as ASHRAE 62.1, ASHRAE 62.2, AS 1668-2, SS 554 provide only recommendations for ventilation for adequate indoor air quality.

All standards covering the topic of thermal comfort (ISO 17772, EN 16798, ASHRAE 55, GB/T 50785, and ISHRAE 10001), provide limiting values for the percent dissatisfied (PD) and operative temperature range for acceptable overall thermal comfort. Local discomfort limitations are also specified in all standards, excluding ISHRAE 10001. While ISO and EN standards prescriptions are more stringent per each category, criteria per GB/T, ASHRAE, and ISHRAE standards are looser (ASHRAE and ISHRAE specify only one acceptable criterion). It is worth to mention that standards provide recommendations for an increase of operative temperatures with elevated air speed. ISO 17772, EN 16798, and ASHRAE 55 regulate personal environmental control that shows the effort of including personal adaptation in standards.

Comparison of the requirements for mechanically conditioned and free-running buildings show that operative temperature recommendations are more adaptable to outdoor conditions for naturally ventilated buildings. While EN 15251 allows variation of operative temperature in the narrowest range per category, ISO 17772, EN 16798 and ASHRAE 55 allow variation of the indoor temperature in a slightly wider range. The range of acceptable temperatures per ASHRAE 55 is shifted towards lower indoor temperatures compared to ISO/EN standards. According to GB/T 50785, the relation between indoor temperature and outdoor temperature depends on the building and the climate zone. Acceptable operative temperatures in free-running buildings in China vary over wider ranges, compared to ISO/EN standards and ASHRAE 55, indicating a higher degree of adaptation of local people. GB/T 50785 standard could be a good example of the standard accounting for local specifics.

Regulation of indoor air quality is included in ISO 17772, EN 15251, EN 16798, ASHRAE 62.1 and 62.2, AS 1668.2, SS 553, SS 554 and ISHRAE 10001. Similarly to thermal comfort-related standards, criteria for percentage dissatisfied are specified for indoor air quality. Category I of the ISHRAE 10001 standard requires the lowest percentage $(5 \%)$ of dissatisfied with the air quality, which is the lowest PD across thermal comfort and IAQ-related standards. Generally, the required ventilation rate and/or level of $\mathrm{CO}_{2}$ concentration is specified as adequate IAQ criteria which can be defined using several methods. Ventilation 
rate based on perceived air quality is the most common method to control air quality, and air flow rates for diluting emissions form occupants are specified for adapted and non-adapted occupants. Obviously, recommendations for adapted people are less stringent. ISO 17772 and EN 16798 provide recommendations for both types of occupants, while EN 15251 provides recommendations for only nonadapted occupants and ASHRAE 62.1 provides recommendations for adapted occupants. As mentioned earlier, ASHRAE 62.1 committee decided that adapted ventilation rates were acceptable while the committee responsible for EN 15251 opted for higher unadapted rates.

While the standards are relatively stringent, there is a lack of coverage of certain topics, particularly related to indoor air quality:

- Diversity factor needs to be included both in thermal comfort and air quality-related requirements

- ISO and EN standards should include more requirements on particulate matter

- It is necessary to highlight the possible negative effects of $\mathrm{CO}_{2}$ at concentrations above $1500 \mathrm{ppm}$

- The use of air cleaning technologies should be extended

- Ventilation requirements for locations or specific times when the outdoor pollution level is high should be separately discussed since $\mathrm{CO}_{2}$ concentration is not an appropriate indicator of indoor air quality in such a case.

These important topics have been studied by the research community, and their inclusion in standards is a matter of timing. ASHRAE standards like 55, 62.1 and 62.2 are on continuous maintenance which means corrections or new additions to a standard could be made within a year. For ISO and CEN standards, it is possible to issue an addendum to the standard within 1-2 years. To revise ISO and EN standards, the scheduled time has been decreased to 3 years.

All in all, the review shows that IEQ parameters such as thermal comfort and air quality are treated separately and without an integrated assessment of various dimensions. Also, the standards focus on perception rather than wellness and productivity. Therefore, there is a need to consider health and performance in standards in the future along with integrating various indoor environmental factors.

\section{Conflicts of Interest Statement:}


The authors whose names are listed immediately below certify that they have NO affiliations with or involvement in any organization or entity with any financial interest (such as honoraria; educational grants; participation in speakers' bureaus; membership, employment, consultancies, stock ownership, or other equity interest; and expert testimony or patent-licensing arrangements), or non-financial interest (such as personal or professional relationships, affiliations, knowledge or beliefs) in the subject matter or materials discussed in this manuscript.

Author names:

\author{
Dolaana Khovalyg, \\ Ongun B. Kazanci, \\ Hanne Halvorsen, \\ Ida Gundlach, \\ William P. Bahnfleth, \\ Jørn Toftum, \\ Bjarne W. Olesen
}

The authors whose names are listed immediately below report the following details of affiliation or involvement in an organization or entity with a financial or non-financial interest in the subject matter or materials discussed in this manuscript. Please specify the nature of the conflict on a separate sheet of paper if the space below is inadequate.

Author names:

References

[1] N. E. Klepeis, "The National Human Activity Pattern Survey (NHAPS) - A Resource for Assessing Exposure to Environmental Pollutants, « Lawrence Berkeley National Laboratory, 2001.

[2] F. P.O., "The philosophy behind a comfort standard.," Proceedings of Indoor Air, årg. 1, pp. 91-98, 1984.

[3] ISO, »ISO 17772-1: Energy performance of buildings - Indoor environmental quality. Part 1: Indoor environmental input parameters for the design and assessment of energy performance in buildings, " ISO, Geneva, 2017.

[4] ISO, »ISO/TR 17772-2:2018: Energy performance of buildings - Overall energy performance assessment procedures. Part 2: Guideline for using indoor environmental input parameters for the design and assessment of energy performance of buildings., "ISO, Geneva, 2018.

[5] Dansk Standard, DS/EN 15251 Indoor environmental input parameters for design and assessment of energy performance of buildings addressing indoor air quality, thermal environment, lighting and acoustics, 1st edition red., Copenhagen: Dansk Standard, 2007.

[6] CEN, EN 16798-1:2019:Energy performance of buildings - Ventilation for buildings - Part 1: Indoor environmental input parameters for design and assessment of energy performance of buildings 
addressing indoor air quality, thermal environment, lighting and acous, CEN, 2019.

[7] CEN, CEN/TR 16798-2:2019: Guideline for using indoor environmental input parameters for the design and assessment of energy performance of buildings, Draft for working group red., BSI, 2019.

[8] ASHRAE, «ANSI/ASHRAE Standard 55-2017 Thermal Environmental Conditions for Human Occupancy, " ASHRAE, Atlanta, 2017.

[9] Dansk Standard, DS/EN ISO 7730 Ergonomics of the thermal environment - Analytical determination and interpretation of thermal comfort using calculation of the PMV and PPD indices and local thermal comfort criteria, 2nd edition red., Copenhagen: Dansk Standard, 2006.

[10] GB/T 50785-2012: Evaluation standard for indoor thermal environment in civil buildings, Ministry of Housing and Urban-Rural Development (MOHURD) and the General Administration of Quality Supervision, Inspection and Quarantine (GAQSIQ) of the People's Republic of China, 2012.

[11] The Building and Construction Standards Committtee, SS 553:2016 - Code of practice for airconditioning and mechanical ventilation in buildings, SPRING Singapore, 2016.

[12] The Building and Construction Standards Committee, SS 554:2016 - Code of practice for indoor air quality for air-conditioned buildings, SPRING Singapore, 2016.

[13] ASHRAE, ANSI/ASHRAE Standard 62.1-2016 Ventilation for Acceptable Indoor Air Quality, Atlanta, GA: ASHRAE, 2016.

[14] ASHRAE, ANSI/ASHRAE Standard 62.2-2016 Ventilation and Acceptable Indoor Air Quality in Residential Buildings, Atlanta, GA: ASHRAE, 2016.

[15] Committee ME-062, AS 1668.2-2012: The use of ventilation and airconditioning in buildings Mechanical ventilation in buildings, STANDARDS Australia, 2012.

[16] ISHRAE, ISHRAE 10001 Indoor Environmental Quality Standard, ISHRAE, 2016.

[17] ASHRAE, "ANSI/ASHRAE Standard 55-2013 Thermal Environmental Conditions for Human Occupancy, " ASHRAE, Atlanta, 2013.

[18] Z. P. ,. M. C. S. ,. I. C. \&. T. S. A. K. Melikov, „Accuracy Limitations for Low-Velocity Measurements and Draft Assessment in Rooms, " HVAC\&R Research, årg. 13, nr. 6, pp. 971-986, 2007. 